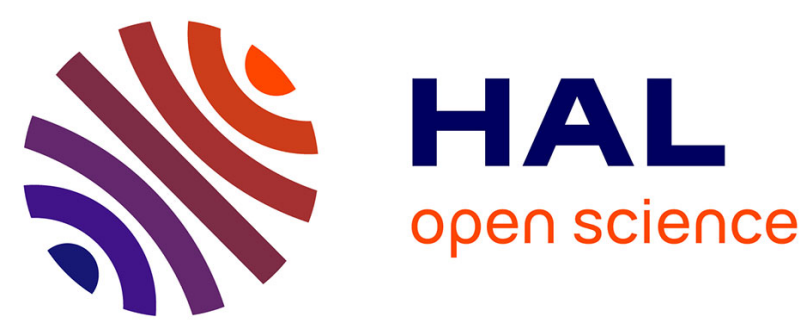

\title{
GEOTRACES intercalibration of neodymium isotopes and rare earth element concentrations in seawater and suspended particles. Part 1: reproducibility of results for the international intercomparison
}

T. van de Flierdt, K. Pahnke, H. Amakawa, P. Andersson, C. Basak, B. Coles, C. Colin, K. Crocket, M. Frank, N. Frank, et al.

\section{To cite this version:}

T. van de Flierdt, K. Pahnke, H. Amakawa, P. Andersson, C. Basak, et al.. GEOTRACES intercalibration of neodymium isotopes and rare earth element concentrations in seawater and suspended particles. Part 1: reproducibility of results for the international intercomparison. Limnology and Oceanography: Methods, 2012, 10, pp.234-251. 10.4319/lom.2012.10.234 . hal-00985401

\section{HAL Id: hal-00985401 https://hal.science/hal-00985401}

Submitted on 30 Apr 2014

HAL is a multi-disciplinary open access archive for the deposit and dissemination of scientific research documents, whether they are published or not. The documents may come from teaching and research institutions in France or abroad, or from public or private research centers.
L'archive ouverte pluridisciplinaire HAL, est destinée au dépôt et à la diffusion de documents scientifiques de niveau recherche, publiés ou non, émanant des établissements d'enseignement et de recherche français ou étrangers, des laboratoires publics ou privés. 


\section{GEOTRACES intercalibration of neodymium isotopes and rare earth element concentrations in seawater and suspended particles. Part 1: reproducibility of results for the international intercomparison}

Tina van de Flierdt ${ }^{1 *}$, Katharina Pahnke ${ }^{2,3}$, and GEOTRACES intercalibration participants: Hiroshi Amakawa ${ }^{4,5}$, Per Andersson ${ }^{6}$, Chandranath Basak $^{7}$, Barry Coles ${ }^{7}$, Christophe Colin ${ }^{8,9}$, Kirsty Crocket ${ }^{1}$, Martin Frank ${ }^{10}$, Norbert Frank ${ }^{9}$, Steven L. Goldstein 11,12, Vineet Goswami'3, Brian A. Haley ${ }^{10}$, 14, Ed C. Hathorne ${ }^{10}$, Sidney R. Hemming ${ }^{11,12}$, Gideon M. Henderson ${ }^{15}$, Catherine Jeandel ${ }^{16}$, Kevin Jones ${ }^{11,12,17}$, Katharina Kreissig ${ }^{1}$, Francois Lacan ${ }^{16}$, Myriam Lambelet ${ }^{1}$, Ellen E. Martin ${ }^{7}$, Derrick R. Newkirk ${ }^{7}$, Haijme Obata ${ }^{4}$, Leopoldo Pena ${ }^{11}$, Alexander M. Piotrowski ${ }^{18}$, Catherine Pradoux ${ }^{16}$, Howie D. Scher ${ }^{19}$, Hans Schöberg ${ }^{6}$, Sunil Kumar Singh ${ }^{13}$, Torben Stichel2,10, Hirofumi Tazoe ${ }^{20}$, Derek Vance ${ }^{21}$, and Jingjing Yang ${ }^{15}$ ${ }^{1}$ Department of Earth Science and Engineering, Imperial College London, South Kensington Campus, London, SW7 2AZ, UK ${ }^{2}$ Department of Geology and Geophysics, University of Hawaii, Honolulu, HI 96822, USA

${ }^{3}$ Max Planck Research Group for Marine Isotope Geochemistry, University of Oldenburg, Carl-von-Ossietzky-Str. 9-11, 26129 Oldenburg, Germany

${ }^{4}$ Atmosphere and Ocean Research Institute, University of Tokyo, 5-1-5 Kashiwanoha, Kashiwa, Chiba 277-8564, Japan ${ }^{5}$ Department of Geosciences, National Taiwan University, No. 1, Sec. 4, Roosevelt Road, Taipei, 10617 Taiwan (R.O.C) ${ }^{6}$ Laboratory for Isotope Geology, Swedish Museum of Natural History, Box 50007, 10405 Stockholm, Sweden ${ }^{7}$ Department of Geological Sciences, University of Florida, Gainesville, FL 32611 USA

${ }^{8}$ Laboratoire des Interactions et Dynamique des Environnements de Surface (IDES), UMR 8148, CNRS-Université de Paris-Sud, Bâtiment 504, 91405 Orsay Cedex, France

${ }^{9}$ Laboratoire des Sciences du Climat et de L'Environnement (LSCE), Laboratoire mixte CNRS-CEA, Avenue de la Terrasse, 91198, Gif-sur-Yvette Cedex, France

${ }^{10}$ IFM-GEOMAR, Leibniz Institute of Marine Sciences at the University of Kiel, Wischhofstraße 1-3, 24148 Kiel, Germany

${ }^{11}$ Lamont-Doherty Earth Observatory of Columbia University, 61 Rt. 9W, Palisades, NY 10964, USA

${ }^{12}$ Department of Earth and Environmental Sciences, Columbia University, 61 Rt. 9W, Palisades, NY 10964, USA

${ }^{13}$ Geosciences Division, Physical Research Laboratory, Navrangpura, Ahmedabad - 380009, India

${ }^{14}$ COAS, OSU, 104 Ocean Admin. Bldg., Corvallis, OR 97209, USA

${ }^{15}$ Department of Earth Sciences, South Parks Road, Oxford, OX1 3AN, UK

${ }^{16}$ LEGOS (CNES/CNRS/IRD/University of Toulouse), 14 Avenue Edouard Belin, 31400, Toulouse, France

${ }^{17}$ ExxonMobil Production Company, 396 West Greens Road, Houston, TX 77067, USA

${ }^{18}$ Godwin Laboratory for Palaeoclimate Research, Department of Earth Sciences, University of Cambridge, Cambridge, CB2 3EQ, UK

${ }^{19}$ Department of Earth and Ocean Sciences and Marine Science Program, University of South Carolina, Columbia, SC 29205, USA

${ }^{20}$ Department of Radiation Chemistry, Institute of Radiation Emergency Medicine, Hirosaki University, 66-1 Hon-cho, Hirosaki, Aomori, Japan

${ }^{21}$ School of Earth Sciences, University of Bristol, Bristol, BS8 1RJ, UK

*Corresponding author: E-mail: tina.vandeflierdt@imperial.ac.uk

\section{Acknowledgments}

We would like to extend a special word of thanks to Bob Anderson, Marty Fleisher, and Tim Kenna for being a great team to work with during this GEOTRACES intercalibration. Thanks also to crew and colleagues who sailed on the two intercalibration cruises on the R/V Knorr, and to Greg Cutter, Ken Bruland, and Rob Sherrell for leading the GEOTRACES intercalibration effort. Thermo Fisher Scientific and Gideon Henderson are thanked for providing the unknown Nd isotope and REE standards. Wafa Abouchami, associate editor Peter Croot, and two anonymous reviewers are thanked for providing constructive reviews. Funding was provided by NSF grant OCE-07-52402 to TvdF and KP, and by Marie Curie International Reintegration grant IRG 230828 and NERC grant NE/F016751/1 to TvdF. This paper is part of the Intercalibration in Chemical Oceanography special issue of $L \& O$ Methods that was supported by funding from the U.S. National Science Foundation, Chemical Oceanography Program (Grant OCE-927285 to G. Cutter).

DOI 10.4319/lom.2012.10.234 


\begin{abstract}
One of the key activities during the initial phase of the international GEOTRACES program was an extensive international intercalibration effort, to ensure that results for a range of trace elements and isotopes (TEIs) from different cruises and from different laboratories can be compared in a meaningful way. Here we present the results from the intercalibration efforts on neodymium isotopes and rare earth elements in seawater and marine particles. Fifteen different laboratories reported results for dissolved ${ }^{143} \mathrm{Nd} /{ }^{144} \mathrm{Nd}$ ratios in seawater at three different locations (BATS $15 \mathrm{~m}$, BATS $2000 \mathrm{~m}$, SAFe $3000 \mathrm{~m})$, with an overall agreement within 47 to $57 \mathrm{ppm}(2 \sigma$ standard deviation of the mean). A similar agreement was found for analyses of an unknown pure $\mathrm{Nd}$ standard solution carried out by 13 laboratories (56 ppm), indicating that mass spectrometry is the main variable in achieving accurate and precise $\mathrm{Nd}$ isotope ratios. Overall, this result is very satisfactory, as the achieved precision is a factor of 40 better than the range of $\mathrm{Nd}$ isotopic compositions observed in the global ocean. Intercalibration for dissolved rare earth element concentrations (REEs) by six laboratories for two water depths at BATS yielded a reproducibility of $15 \%$ or better for all REE except Ce, which seems to be the most blank-sensitive REE. Neodymium concentrations from 12 laboratories show an agreement within 9\%, reflecting the best currently possible reproducibility. Results for Nd isotopic compositions and REE concentrations on marine particles are inconclusive, and should be revisited in the future.
\end{abstract}

The neodymium isotopic composition of seawater has been of interest to the scientific community for more than three decades. The feasibility to directly measure $\mathrm{Nd}$ isotopes in seawater was first demonstrated by Piepgras et al. (1979). It was these measurements, alongside indirect studies of seawater $\mathrm{Nd}$ isotopes based on fish debris (DePaolo and Wasserburg 1977) and ferromanganese nodules (O'Nions et al. 1978) from which the picture emerged that the ${ }^{143} \mathrm{Nd} /{ }^{144} \mathrm{Nd}$ isotope ratio in the different ocean basins is closely coupled to that of the surrounding continents. The provinciality between different ocean basins implied by the early data (see also Piepgras and Wasserburg 1980) has been verified and refined in many studies since, and points to a residence time of $\mathrm{Nd}$ in seawater on the order of, or shorter than, the global turnover time of the ocean (500-1000 y; Tachikawa et al. 2003). The lowest values for dissolved $\mathrm{Nd}$ isotopes are observed around the old cratons in the North Atlantic (Stordal and Wasserburg 1986), while the highest values are found next to young volcanic areas in the Pacific (Piepgras and Jacobsen 1988; Vance et al. 2004), yielding an overall range in the global ocean of more than 20 epsilon units $\left({ }^{143} \mathrm{Nd} /{ }^{144} \mathrm{Nd}\right.$ ratios are expressed in epsilon units, which denotes the deviation of a sample ${ }^{143} \mathrm{Nd} /{ }^{144} \mathrm{Nd}$ ratio from the "CHondritic Uniform Reservoir" value in parts per 10000; CHUR = 0.512638; Jacobsen and Wasserburg 1980).

However, uncertainties remain when trying to exploit dissolved $\mathrm{Nd}$ isotopes as a tracer for water mass mixing (Goldstein and Hemming 2003), or as a tracer for continental inputs and exchange with the ocean margins (Lacan and Jeandel 2005). Our current understanding of sources, sinks, and especially of the internal cycling of $\mathrm{Nd}$ in the ocean is relatively poor, mainly due to a scarce number of observations. As of today, only 700 measurements on dissolved $\mathrm{Nd}$ isotopes are published from the global ocean, more than a quarter of which are surface water samples. Furthermore, the geographic spread of sampling locations is very poor with $\sim 50 \%$ of all depth profiles being located in the North Atlantic and the North Pacific Ocean.

The international GEOTRACES program is bound to improve this situation, as its three research objectives are defined as follows (GEOTRACES Science Plan 2006):

(1) To determine global ocean distributions of selected trace elements and isotopes (TEIs), including their concentration, chemical speciation, and physical form, and to evaluate the sources, sinks, and internal cycling of these species to characterize more completely the physical, chemical, and biological processes regulating their distributions;

(2) To understand the processes involved in oceanic traceelement cycles sufficiently well that the response of these cycles to global change can be predicted, and their impact on the carbon cycle and climate understood; and

(3) To understand the processes that control the concentrations of geochemical species used for proxies of the past environment, both in the water column and in the substrates that reflect the water column.

A set of 'key TEIs' (Trace Elements and Isotopes; among them dissolved $\mathrm{Nd}$ isotopes) considered central to these broader goals of GEOTRACES were identified and have to be measured on every GEOTRACES cruise (GEOTRACES Science Plan 2006). Before the start of the major field program, a phase of intercalibration activities was launched for a number of TEIs, including all 'key TEIs'.

No international intercalibration has ever been carried out for $\mathrm{Nd}$ isotopes - neither for seawater, nor in hard rocks. The hard rock community could overcome this problem by analyses of readily available USGS reference materials (e.g., BCR-1 and 2, BHVO-1 and 2, AGV-1 and 2, G-2, GSP-2; see Weis et al. 2006 for a recent example). No reference material however is available that resembles the matrix of seawater and requires analytical procedures to extract small abundances of REE from a large volume of sample. Here we report the results on the GEOTRACES 
intercalibration efforts for dissolved Nd isotopes, which include a total of 15 participating laboratories, some of which have a long-standing history of seawater $\mathrm{Nd}$ isotope measurements, and some of which are relatively new to the field.

Although not one of the key parameters of the GEOTRACES program, the REE concentrations in seawater have been historically used by a large number of laboratories to decipher lateral and vertical processes in the water column as well as water mass provenance (e.g., Elderfield and Greaves 1982; Piepgras and Jacobsen 1992; Alibo and Nozaki 1999). We therefore used the opportunity offered by the $\mathrm{Nd}$ isotope study to gather intercalibration data on dissolved rare earth element concentrations (REEs), as well as $\mathrm{Nd}$ isotopic compositions and REE concentrations from marine particles.

Our goal was to assess the precision and accuracy possible for dissolved and particulate Nd isotopes (and REEs). Following documentation and assessment of the data, we will present some recommendations to achieve precise and accurate results on future GEOTRACES cruises. This article is accompanied by a second article that takes a closer look at the seagoing side of achieving accurate and precise results for dissolved and particulate $\mathrm{Nd}$ isotopes and $\mathrm{REE}$, by presenting results on systematic tests on different materials and methods involved (Pahnke et al. 2012). The second article also presents the first GEOTRACES baseline profiles for Nd isotopes (and REEs) for the Bermuda Atlantic Time-Series Station (BATS) in the NW Atlantic Ocean and the SAFe station (Sampling and Analysis of Fe) in the Pacific Ocean.

\section{Materials and procedures}

\section{Shipboard sampling of seawater and particles}

Samples used during this intercalibration exercise were collected on two GEOTRACES intercalibration cruises, carried out on the R/V Knorr in June-July 2008 in the Atlantic Ocean (Bermuda-Norfolk, KN193-6), and in May 2009 in the Pacific Ocean (Honolulu-San Diego, KN195-8). The two cruises were chosen to sample fundamentally different water masses and biogeochemical regimes and to occupy previously well characterized time-series stations in the Atlantic Ocean (BATS) and the Pacific Ocean (SAFe).

For intercalibration of $\mathrm{Nd}$ isotopes and REE concentrations, both dissolved and particulate samples were collected. For dissolved samples, large volumes of filtered and homogenized seawater were collected from three different locations: BATS deep water $(2000 \mathrm{~m})$, BATS sub-surface water $(15 \mathrm{~m})$, and SAFe deep water (3000 m). Deep water samples were collected using multiple casts of the trace metal clean GEOTRACES rosette deployed on a Kevlar hydroline, whereas sub-surface water was collected using the UCSC designed "GeoFish" towed sampling system. Filtration of seawater was carried out using 0.2 $\mu \mathrm{m}$ Osmonics cartridge filters in a portable clean van environment. Water from the same water depth was transferred through Teflon tubing into two interconnected $500 \mathrm{~L}$ tanks made of fluorinated low density polyethylene, which were homogenized using an all PFA Teflon diaphragm pump (UCSC SAFe tanks). Homogenized 500-1000 L of seawater were acidified to $\mathrm{pH}<2$ using ultrapure Seastar $\mathrm{HCl}$. Individual sample containers ranged from $0.5 \mathrm{~L}$ to $20 \mathrm{~L}$, and were provided and precleaned by the individual intercalibration participants. Overall, most laboratories received $2 \times 10 \mathrm{~L}$ seawater from each of the three locations for duplicate analyses of $\mathrm{Nd}$ isotopes, and $0.5 \mathrm{~L}$ of seawater for REE concentration measurements. Filling of individual sample containers was performed directly from the SAFe tanks under a tent on deck the R/V Knorr.

Particle samples were derived from the three following locations: BATS deep water $(2000 \mathrm{~m})$, BATS sub-surface water $(30 \mathrm{~m})$, and Virgina slope water $(98 \mathrm{~m})$. Two complementary pumping systems were deployed for Nd isotope and REE intercalibration purposes: McLane pumps (deep water location at BATS), and MULVFS (Multiple Unit Large Volume Filtration System; other two location) (Maiti et al. 2012; Bishop et al. 2008). Using the McLane pumps, about $600 \mathrm{~L}$ seawater were pumped through each $0.45 \mu \mathrm{m}$ Supor filter (142 mm diameter). Filters were dried onboard in a dedicated clean environment, and cut into halves using a PVC template fitted with a ceramic knife (pie-cutter). Each laboratory participating in the $\mathrm{Nd}$ isotope intercalibration was provided half of a filter and half of a corresponding dipped blank. For REE intercalibration, $2 \mathrm{~cm}$ punches, corresponding to $\sim 20 \mathrm{~L}$ pumped seawater, were taken out of a few of the filter halves for REE measurements (e.g., some of the isotope laboratories received slightly smaller samples). Larger water volumes (>1000 L) were pumped with the MULVFS system, equipped with large quartz fiber filters (QMA; $506.7 \mathrm{~cm}^{2}$ area, $1 \mu \mathrm{m}$ pore size). Four $4.5 \mathrm{~cm}$ punches were taken out of the filters for $\mathrm{Nd}$ isotope samples, representing $\sim 380 \mathrm{~L}$ pumped water volume, accompanied by two $2.5 \mathrm{~cm}$ punches from dipped blanks. For REE measurements, four $1.2 \mathrm{~cm}$ punches ( $27 \mathrm{~L}$ pumped water volume) were collected from dried filters together with two $1.2 \mathrm{~cm}$ punches from dipped blanks. All filters were stored and shipped in precleaned containers.

Shore-based methods to determine dissolved and particulate $\mathrm{Nd}$ isotopic compositions and REE concentrations

As this article documents the first intercalibration effort for Nd isotopes (and REE concentrations) in seawater and marine particles, no particular analytical method was prescribed. This approach allowed a variety of routine procedures to be compared (e.g., different sample preconcentration, ion chromatography, and mass spectrometry procedures). Below we briefly summarize the main differences in the analytical methods applied. Methodological information for each anonymized laboratory can be found in Tables $1 \mathrm{a}$ and $1 \mathrm{~b}$.

Neodymium isotope measurements in seawater samples

To preconcentrate Nd from the seawater matrix most laboratories performed a Fe coprecipitation step, where Fe is added to seawater, most typically as $\mathrm{FeCl}_{3}$ and equilibrated for 24-48 h. A subsequent increase to a $\mathrm{pH}$ of $\sim 8$, using ultraclean 
Table 1a: Details for processing seawater samples for their $\mathrm{Nd}$ isotopic composition in different laboratories.

\begin{tabular}{|c|c|c|c|c|c|c|}
\hline lab & spike & preconcentration of $\mathrm{Nd}$ & \multicolumn{2}{|c|}{ ion chromatography } & \multirow{2}{*}{$\begin{array}{c}\begin{array}{c}\text { mass } \\
\text { spectrometry }\end{array} \\
\text { TIMS }\left(\mathrm{Nd}^{+}\right) / \\
\mathrm{MC}-\mathrm{ICP}_{\mathrm{C}} \mathrm{MS}\end{array}$} & \multirow{2}{*}{$\begin{array}{l}\text { blank } \\
<20 \mathrm{pg}\end{array}$} \\
\hline 1 & NA & $\begin{array}{c}\text { Fe co-precipitation } \\
\text { (100 mg Fe for 20L of seawater) }\end{array}$ & cation exchange & DEP column & & \\
\hline 2 & mixed ${ }^{150} \mathrm{Nd}-{ }^{149} \mathrm{Sm}$ & $\begin{array}{c}\text { Fe co-precipitation } \\
\text { (8 mg Fe per litre of seawater) }\end{array}$ & cation exchange & Ln Spec & MC-ICP-MS & $\begin{array}{c}30 \mathrm{pg} \\
\left(275 \mathrm{pg}^{*}\right)\end{array}$ \\
\hline 3 & NA & $\begin{array}{c}\text { Fe co-precipitation } \\
\text { (50 mg Fe for } 10 \mathrm{~L} \text { of seawater) }\end{array}$ & RE Spec & $\alpha-\mathrm{HIBA}$ & TIMS $\left(\mathrm{NdO}^{+}\right)$ & $3 \mathrm{pg}$ \\
\hline $4^{a}$ & NA & $\begin{array}{c}\text { Fe co-precipitation } \\
\text { (50 mg Fe for 10L of seawater) }\end{array}$ & cation exchange & Ln Spec & MC-ICP-MS & $<2 \mathrm{pg}$ \\
\hline $4^{b}$ & NA & $\begin{array}{l}\text { preconcentrated } 10 \mathrm{~L} \\
\text { on } \mathrm{C} 18 \text { cartridge }\end{array}$ & NA & Ln Spec & MC-ICP-MS & ND \\
\hline 5 & $\begin{array}{c}\text { spiked samples } 511 \text { and } 311 \\
\text { with } 250 \mu \mathrm{g}{ }^{9} \mathrm{Be}\end{array}$ & \multicolumn{3}{|c|}{$\begin{array}{l}\text { anion exchange, cation exchange, } \\
\text { TRU spec column, Ln Spec column, } \\
\text { Eichrom prefilter material }\end{array}$} & TIMS $\left(\mathrm{Nd}^{+}\right)$ & 70 pg \\
\hline 6 & ${ }^{150} \mathrm{Nd},{ }^{147} \mathrm{Sm}$ & $\begin{array}{c}\text { Fe co-precipitation } \\
\text { (14 mg Fe for } 3.6 \mathrm{~L} \text { seawater) }\end{array}$ & \multicolumn{2}{|c|}{$\begin{array}{c}\text { anion exchange, TRU Spec, } \\
\text { Ln Spec }\end{array}$} & TIMS $\left(\mathrm{Nd}^{+}\right)$ & $\begin{array}{c}8-12 p^{a} \\
4 p q^{b}\end{array}$ \\
\hline $7^{\mathrm{a}}$ & NA & $\begin{array}{c}\text { Fe co-precipitation } \\
\text { (60 mg Fe for } 10 \mathrm{~L} \text { seawater) }\end{array}$ & \multicolumn{2}{|c|}{$\begin{array}{l}\text { cation exchange, Mitsubishi } \\
\text { resion, Ln Spec }\end{array}$} & MC-ICP-MS & $2.5 \mathrm{pg}$ \\
\hline $7^{\mathrm{b}}$ & NA & $\begin{array}{l}\text { preconcentrated 10L } \\
\text { on C18 cartridge }\end{array}$ & NA & Ln Spec & MC-ICP-MS & $2.5 \mathrm{pg}$ \\
\hline 8 & NA & $\begin{array}{l}\text { preconcentrated } 10 \mathrm{~L} \\
\text { on } \mathrm{C} 18 \text { cartridge }\end{array}$ & cation exchange & Ln Spec & $\begin{array}{l}\text { TIMS }\left(\mathrm{Nd}^{+}\right) / \\
\text {MC-ICP-MS }\end{array}$ & $187 \mathrm{pg}$ \\
\hline 9 & NA & Fe co-precipitation & \multicolumn{2}{|c|}{$\begin{array}{l}\text { anion exchange, cation exchange } \\
(x 2) \text {, Ln Spec column }\end{array}$} & TIMS $\left(\mathrm{Nd}^{+}\right)$ & $120 \mathrm{pg}$ \\
\hline 10 & NA & $\begin{array}{c}\text { Fe co-precipitation } \\
\text { (1 mg Fe per litre of seawater) }\end{array}$ & TRU Spec & Ln Spec & MC-ICP-MS & ND \\
\hline 11 & NA & $\begin{array}{c}\text { Fe co-precipitation } \\
\text { (50 mg Fe for 10L of seawater) }\end{array}$ & RE Spec & $\alpha-\mathrm{HIBA}$ & TIMS (NdO') & $3 \mathrm{pg}$ \\
\hline 12 & NA & $\begin{array}{l}\text { preconcentrated } 10 \mathrm{~L} \\
\text { on } \mathrm{C} 18 \text { cartridge }\end{array}$ & TRU Spec & Ln Spec & TIMS $\left(\mathrm{NdO}^{+}\right)$ & $\begin{array}{l}7 \mathrm{pg}^{\mathrm{c}} \\
20 \mathrm{pq}^{\mathrm{d}}\end{array}$ \\
\hline 13 & NA & $\begin{array}{l}\text { preconcentrated } 10 \mathrm{~L} \\
\text { on } \mathrm{C} 18 \text { cartridge }\end{array}$ & cation exchange & Ln Spec & MC-ICP-MS & $8 \mathrm{pg}$ \\
\hline 14 & NA & $\begin{array}{c}\text { Fe co-precipitation } \\
\text { (0.5 g Fe per } 20 \mathrm{~L} \text { of seawater) }\end{array}$ & cation exchange & Ln Spec & MC-ICP-MS & ND \\
\hline 15 & NA & $\begin{array}{l}\text { preconcentrated } 10 \mathrm{~L} \\
\text { on } \mathrm{C} 18 \text { cartridge }\end{array}$ & cation exchange & Ln Spec & TIMS $\left(\mathrm{Nd}^{+}\right)$ & $<300 \mathrm{pg}$ \\
\hline
\end{tabular}

* blank of Fe solution, which was measured for its isotopic composition and would imply a correction of 0.02 to 0.1 epsilon units, which the lab refrained from applying; remaining analytical blank (chemistry and mass spectrometry): 30pg

${ }^{a}$ method used for intercalibration samples from BATS

${ }^{b}$ method used for intercalibration samples from SaFE

${ }^{c}$ column chemistry and loading blank

d total procedural blank derived from pumping $10 \mathrm{~L}$ ultraclean water through two cartridges and subtracting the water blank $\mathrm{ND}=$ not determined; NA = not applicable

ammonium hydroxide leads to the formation of iron hydroxides, which in turn, efficiently scavenge rare earth elements out of the seawater solution (e.g., Piepgras and Wasserburg 1987). Depending on the laboratory, between 1 and $25 \mathrm{mg}$ purified Fe are added per liter of seawater. Purification of Fe is typically carried out by isopropyl ether back-extraction (Dodson et al. 1936), or by ion exchange chromatography. Lack of careful purification has been reported as the most likely can- didate to introduce a significant procedural blank (e.g., a few hundred picograms; see Table 1a). A few laboratories choose to concentrate $\mathrm{Nd}$ from the seawater matrix by liquid-liquid extraction, pumping $10 \mathrm{~L}$ seawater aliquots, adjusted to a $\mathrm{pH}$ of $\sim 3.5$, through two coupled Sep-Pack C18 cartridges, each filled with $300 \mathrm{mg}$ of a mixture of $65 \%$ bis(2-ethylhexyl) hydrogen phosphate (HDEHP) and 35\% 2-ethylhexyl dihydrogen phosphate $\left(\mathrm{H}_{2} \mathrm{MEHP}\right)$, at a speed of $20 \mathrm{~mL} / \mathrm{min}$ (Sha- 


\begin{tabular}{|c|c|c|c|c|c|}
\hline lab & concentrations & aliquoting & spike & technique & mass spectrometry \\
\hline 1 & [REE] & $4 \mathrm{~mL}$ aliquot & no & $\begin{array}{l}\text { seaFAST system with a column containing resin with } \\
\text { ethylenediaminetriacetic acid and iminodiacetic acid } \\
\text { functional groups to preconcentrate REE }\end{array}$ & ICP-MS \\
\hline 2 & {$[\mathrm{Nd}],[\mathrm{Sm}]$} & \multicolumn{3}{|c|}{ spiked large volume sample for isotope work with ${ }^{150} \mathrm{Nd}$ and ${ }^{149} \mathrm{Sm}$ and processed as described in Table 1a } & MC-ICP-MS \\
\hline 3 & [REE] & 50 to $150 \mathrm{~mL}$ aliquot & $\begin{array}{l}\text { mixed REE spike }\left({ }^{138} \mathrm{La},{ }^{142} \mathrm{Ce},{ }^{145} \mathrm{Nd},{ }^{149} \mathrm{Sm},{ }^{153} \mathrm{Eu}\right. \\
\left.{ }^{155} \mathrm{Gd},{ }^{161} \mathrm{Gd},{ }^{167} \mathrm{Er} \text {, and }{ }^{171} \mathrm{Yb}\right)\end{array}$ & $\begin{array}{c}\text { co-precipitated REE with } \mathrm{Fe} ; \mathrm{RE} \text { spec ion } \\
\text { chromatography with added ascorbic acid to reduce } \\
\mathrm{Fe}\end{array}$ & MC-ICP-MS \\
\hline 5 & [REE] & $500 \mathrm{ml}$ aliquot & ${ }^{145} \mathrm{Nd}$ and Indium & $\begin{array}{l}\text { solvent extraction following Shabani et al (1992) } \\
\text { except for sample } 513 \text {, for which REE were co- } \\
\text { precipitated with } 8 \mathrm{mg} \text { of or Fe followed by anion } \\
\text { exchange chemistry }\end{array}$ & ICP-MS \\
\hline 6 & {$[\mathrm{Nd}],[\mathrm{Sm}]$} & \multicolumn{3}{|c|}{ spiked entire sample with ${ }^{150} \mathrm{Nd}$ and ${ }^{147} \mathrm{Sm}$ and processed as described in Table 1a } & TIMS \\
\hline 8 & [REE] & $500 \mathrm{~mL}$ aliquot & ${ }^{150} \mathrm{Nd},{ }^{172} \mathrm{Yb}$ & $\begin{array}{c}\text { co-precipitated REE with } 2.5 \mathrm{mg} \mathrm{Fe} \text {; anion exchange } \\
\text { column }\end{array}$ & ICP-MS \\
\hline 9 & {$[\mathrm{Nd}]$} & $500 \mathrm{~mL}$ aliquot & ${ }^{145} \mathrm{Nd}$ & co-precipitated REE with Fe; anion exchange column & ICP-MS \\
\hline 10 & [REE] & $600 \mathrm{~mL}$ aliquot & $\sim 20 \mu \mathrm{g}$ Tm solution (100.2 ppm) & co-precipitated REE with $1 \mathrm{ml}$ 1000ppm Fe solution & ICP-MS \\
\hline 11 & {$[\mathrm{Nd}]$} & $250 \mathrm{~mL}$ aliquot & ${ }^{146} \mathrm{Nd}$ & co-precipitated REE with Fe; RE Spec column & ICP-MS \\
\hline 12 & {$[\mathrm{Nd}]$} & \multicolumn{3}{|c|}{ spiked large volume for isotope work with ${ }^{150} \mathrm{Nd}$ and processed as described in Table 1a } & TIMS \\
\hline 16 & [REE] & $180-190 \mathrm{~g}$ of seawater & ${ }^{145} \mathrm{Nd},{ }^{171} \mathrm{Yb}$ & co-precipitated REE with Fe; anion exchange column & ICP-MS \\
\hline $17^{*, a}$ & [REE] & $\begin{array}{l}10 \mathrm{~L} \text { of seawater; used a fraction of the REE } \\
\text { cut from column chemistry }\end{array}$ & no & $\begin{array}{l}\text { co-precipitated REE with Fe; cation exchange column, } \\
\text { Mitsubishi resin column; Re and Rh as internal } \\
\text { standards }\end{array}$ & ICP-MS \\
\hline $17^{\mathrm{b}}$ & {$[\mathrm{Nd}]$} & $500 \mathrm{~mL}$ aliquot & ${ }^{150} \mathrm{Nd}$ & $\begin{array}{c}\text { preconcentration of REE on C-18 cartridges; Ln Spec } \\
\text { column }\end{array}$ & MC-ICP-MS \\
\hline
\end{tabular}

* seawater concentrations were calculated assuming a total sample volume of $10 \mathrm{~L}$ for the two intercalibration samples from BATS

${ }^{a}$ method used for intercalibration samples from BATS

${ }^{b}$ method used for analyses of unknown REE standard

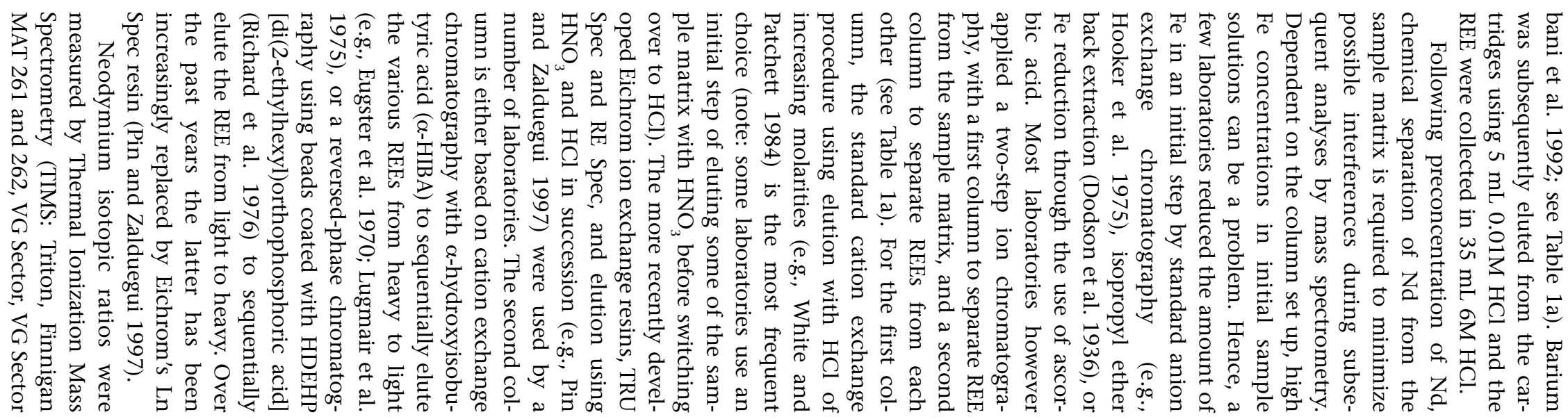


54) or Multiple Collector Inductively Coupled Plasma Mass Spectrometry (MC-ICP-MS: Nu Plasma or Neptune). While historically TIMS was the method of choice for all laboratories, the past $15 \mathrm{y}$ have seen a quick rise of MC-ICP-MS as a replacement for many routine analyses previously performed by TIMS. Arguments in favor of MC-ICP-MS measurements are the speediness of data collection achieved by significantly reduced analysis time, while maintaining a similar precision to that achieved by TIMS (for a summary on MC-ICP-MS, see Halliday et al. 2000). The advantage of TIMS measurements, especially when considering improved ionization during neodymium oxide measurements $\left(\mathrm{NdO}^{+}\right)$compared with metal runs $\left(\mathrm{Nd}^{+}\right)$, is the ability to return high precision data on small abundance samples (e.g., Li et al. 2007; Chu et al. 2009; Harvey and Baxter 2009). Extensive literature exists on appropriate measurement setups, especially on eliminating the relatively large mass discrimination effect observed for measurements by MC-ICP-MS (e.g., Vance and Thirlwall 2002; Wombacher and Rehkämper 2003) and on carrying out the numerous oxide interference corrections and using the appropriate oxygen isotopic composition during TIMS measurements (e.g., Thirlwall 1991a, 1991b). Discussing the details of applied mass spectrometry between the 15 participating laboratories goes beyond the scope of this article and would violate agreed anonymity. It is, however, important to note that all laboratories corrected for instrumental mass bias using a ${ }^{146} \mathrm{Nd} /{ }^{144} \mathrm{Nd}$ of 0.7219 (O'Nions et al. 1977), making the results directly comparable.

\section{Neodymium isotope measurements in marine particles}

The main difference in processing marine particles for their $\mathrm{Nd}$ isotopic composition, compared with seawater samples, is the initial sample dissolution step. As different digestion and leaching methods of filters are likely to result in varying amounts of REE being removed from the particles on the filters, two methods were prescribed for the particle samples from deep waters at BATS and shallow water at BATS, respectively. For the Supor filters (deep water particles at BATS), a total digest of the filter was targeted by following the method used by Cullen and Sherrell (1999). Briefly, filters were placed in precleaned Teflon vials together with a mixture of concentrated $\mathrm{HNO}_{3}$ and concentrated $\mathrm{HF}$ (19:1). Complete digestion of any particles was achieved by refluxing at $120^{\circ} \mathrm{C}$ for $4 \mathrm{~h}$. This procedure also leads to a total digestion of the Supor filter, which however does not constitute a major blank issue (see "Assessment and discussion of results" below). One laboratory deviated from this procedure and instead followed a digestion method adapted from Landing and Lewis (1991) that avoids total digestion of the filter material (Table 5). The large blank of quartz fiber filters (QMA) in contrast precludes total digestion, and the approach chosen targets a leaching of the REE fraction not bound to the silicate phases (Collier and Edmond 1984). As described in Jeandel et al. (1995), samples were leached in $0.6 \mathrm{M} \mathrm{HCl}$ at $60^{\circ} \mathrm{C}$ for $20 \mathrm{~h}$. For the third set of filters from the Virginia slope station, individual laboratories were free to choose a different method. The only deviation from above outlined methods for samples from the Virginia slope station was performed however by laboratory number 2 , where QMA filters were leached for $3.5 \mathrm{~h}$ at $90^{\circ} \mathrm{C}$ in a mixture of $0.005 \mathrm{M}$ hydroxylamine hydrochloride, $1.5 \%$ acetic acid, and $2 \mathrm{nM}$ EDTA solution ( $\mathrm{pH}$ of 3.5), with an ultrasonification step performed every hour.

Rare earth element concentration measurements in seawater samples

In general, the procedure for determining REE concentrations on seawater samples can follow a similar methodology to the one described above for the first steps in determining the Nd isotopic composition. Most laboratories use Fe coprecipitation or liquid-liquid extraction to preconcentrate the REE, followed by ion exchange chromatography to separate the REE fraction from the sample matrix (typically anion exchange or RE Spec; Table 1b).

The major difference between isotope and concentrations measurements is the smaller water volume required for concentration analyses (between $4 \mathrm{~mL}$ and $600 \mathrm{~mL}$; Table 1b), and the addition of an isotopically enriched tracer ("spike") before preconcentration. This addition is crucial to correct for elemental fractionation, which may happen during preconcentration and/or ion chromatography. The types of spikes used for this intercalibration exercise include multi-element mixed REE isotope spikes, two-element isotope spikes, and the addition of monoisotopic elements (Table 1b). Traditionally, REE concentrations were analyzed by isotope dilution methods and TIMS (e.g., Elderfield and Greaves 1982), but for this intercalibration, REE patterns were mostly analyzed by ICP-MS (Agilent 7500, Element 2, HP-4500, Perkin Elmer Elan DRCII, Yokogawa PMS-2000). Five laboratories report results for $\mathrm{Nd}$ concentrations only, which in three cases, were determined on the same large volume sample used for isotopic analyses through spiking before coprecipitation. In these cases, measurements were performed by TIMS/MC-ICP-MS.

Notably, one laboratory ( $\mathrm{nr}$ 1) used the seaFAST system, a commercially available system (Elemental Scientific) with a column containing a resin with ethylendiaminetriacetic acid and iminodiacetic acid functional groups to preconcentrate REEs. This system can be directly connected to an ICP-MS, and blanks, standards, and samples are passed through the column in the same manner, and eluted directly into the spray chamber of the ICP-MS.

\section{Rare earth element concentration measurements in marine} particles

Rare earth element concentrations of marine particles were attempted by four laboratories. Partial return of data, as well as some deviation from recommended methodologies, yielded a poor statistical basis for assessing the results. We, therefore, refrain from reporting the actual values in the article, but will make some qualitative comments on the results in the next sections to encourage and guide future efforts. 


\section{Assessment and discussion of results}

Neodymium isotope intercalibration in seawater at BATS and SAFe

To achieve comparability of results, all measured ${ }^{143} \mathrm{Nd} /{ }^{144} \mathrm{Nd}$ ratios have been normalized relative to a $\mathrm{JNd}_{\mathrm{i}}$ ratio of 0.512115 (Tanaka et al. 2000) or a La Jolla ratio of 0.511858 (Lugmair et al. 1983) using standard values reported by each laboratory (see caption of Table 2). For laboratories that routinely use other in-house standards than the ones listed above, their reported cross-calibration for their respective standards relative to $\mathrm{JNd}_{\mathrm{i}} / \mathrm{La}$ Jolla was used. Figs. 1 and 2 and Tables 2 and 3 show the results for the Nd isotopic composition of seawater at three distinct water depths at BATS and SAFe as measured by 15 different laboratories. Sub-surface water at BATS yielded an average $\mathrm{Nd}$ isotopic composition of $-9.2 \pm 0.6$, deep water at BATS a value of $-13.1 \pm 0.6$, and the average Nd isotopic composition of deep water at SAFe is $-3.2 \pm 0.5$ (errors:
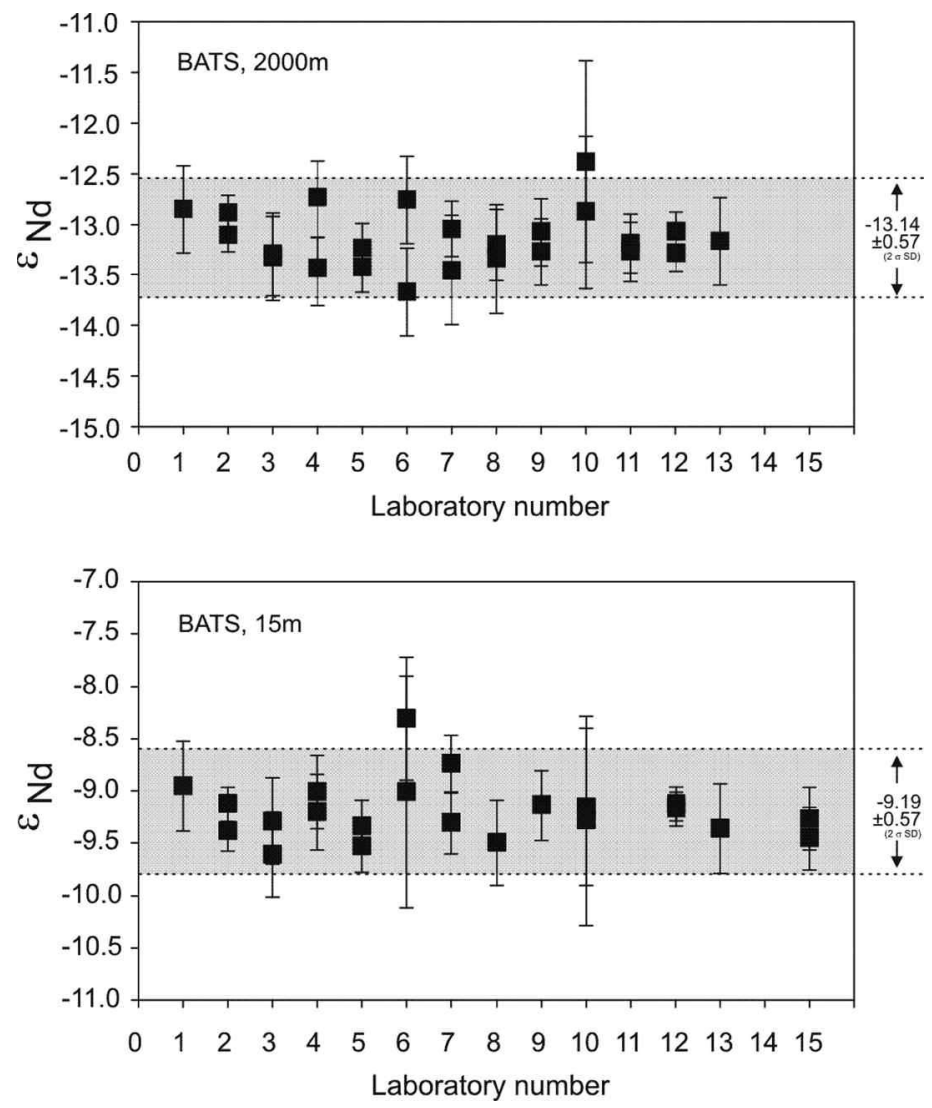

Fig. 1. Dissolved neodymium isotopic composition for two water depths at BATS (NW Atlantic). Results display good agreement of the international community (15 individual laboratories) on measuring the $\mathrm{Nd}$ isotopic composition of seawater (i.e., values agree within $57 \mathrm{ppm}$; two sigma standard deviation of the mean). Details on samples and laboratories are given in Tables $1 \mathrm{a}$ and 2. Errors plotted are external two sigma standard deviations reported by each laboratory (based on repeat analyses of isotopic standards; see Table 2 caption), or internal two sigma standard error, depending on which error was the larger one. two sigma standard deviations of the mean). Interpretation of the results concerning comparability to published literature values can be found in the accompanying paper by Pahnke et al. (2012). Here we focus on assessing the agreement achieved between the different laboratories (i.e., reproducibility; reproducibility is here defined as the two sigma standard deviation of the mean of all individual data points considered for a given location).

The reproducibility for the three sample sets is found to be between 47 and $57 \mathrm{ppm}$. Considering that the external two sigma standard deviation reported by each laboratory for ${ }^{143} \mathrm{Nd} /{ }^{144} \mathrm{Nd}$ ratios varies between 10 and $100 \mathrm{ppm}$ (see values reported on La Jolla, $\mathrm{JNd}_{\mathrm{i}}$, or other in house standard runs in the caption of Tables 2 and 3), this is an excellent result. However, two thirds of all laboratories report a more narrow range of external reproducibilities between 20 and 40 ppm for their ${ }^{143} \mathrm{Nd} /{ }^{144} \mathrm{Nd}$ analyses. Two questions emerge at this point: (1) Is a better agreement of natural seawater measurements possible (e.g., what is the reproducibility on natural samples compared to pure standard solutions and how do various methodologies feature in the statistics?), and (2) what is the reason for the larger external errors reported by some laboratories, and how do their values influence the overall statistics.

Starting with the first point, a simple exercise was undertaken to constrain whether the spread in data observed in Figs. 1 and 2 is an artifact of incomplete matrix removal from natural samples during ion chromatography, and subsequent mass spectrometry, or whether the spread in ${ }^{143} \mathrm{Nd} /{ }^{144} \mathrm{Nd}$ ratios arises from the analyses themselves (i.e., different methods applied during mass spectrometry yielding different degrees of accuracy and precision). Fig. 3 illustrates results obtained for an 'unknown standard solution'. The standard was produced from $\mathrm{Nd}_{2} \mathrm{O}_{3}$ powder at Imperial College London in an ultraclean lab-

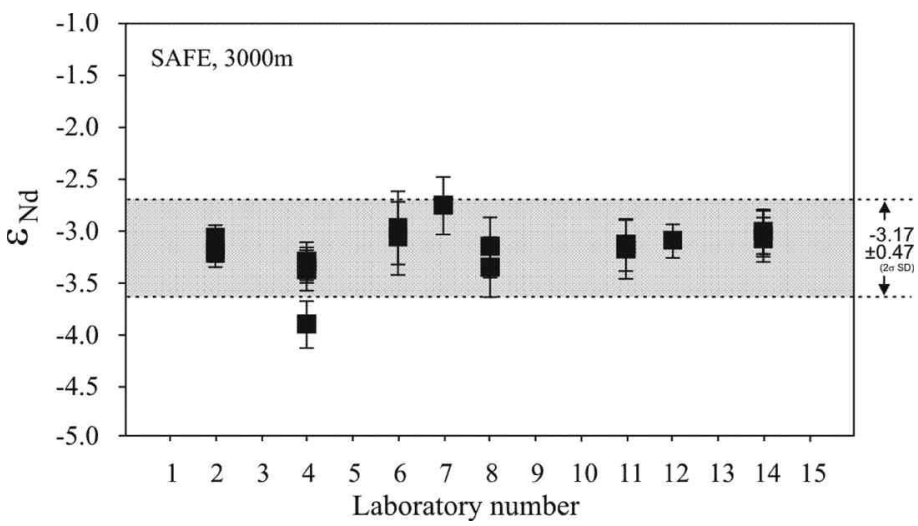

Fig. 2. Dissolved neodymium isotopic composition at $3 \mathrm{~km}$ water depth at SAFe (NE Pacific). Results display good agreement of the international community (8 individual laboratories) on measuring the $\mathrm{Nd}$ isotopic composition of seawater (i.e., all values agree within 47 ppm; two sigma standard deviation of the mean). Details on samples and laboratories are given in Tables $1 \mathrm{a}$ and 3. Errors plotted are external two sigma standard deviations reported by each laboratory (based on repeat analyses of isotopic standards; see Table 3 caption). 
Table 2: International intercalibration for $\mathrm{Nd}$ isotopes in seawater at BATS.

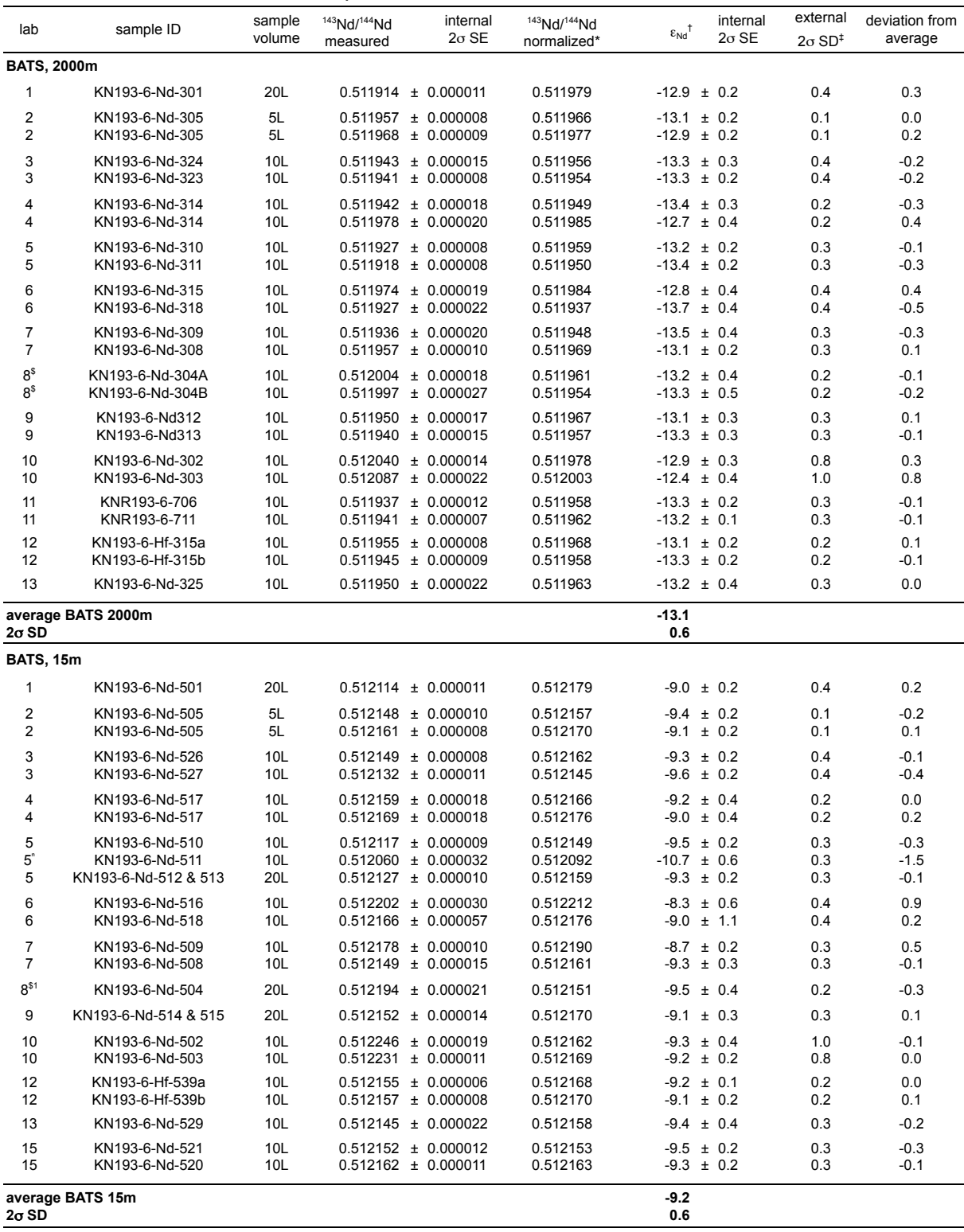

${ }^{*}{ }^{143} \mathrm{Nd} /{ }^{144} \mathrm{Nd}$ ratios were normalized using the reported standard data for each lab, relative to a JNdi value of 0.512115 (Tanaka et al., 2000) or a La Jolla value of 0.511858 (Lugmair et al., 1983).

$\varepsilon_{\text {Nd }}$ values were calculated relative to a CHUR of 0.512638 (Jacobsen and Wasserburg, 1980).

${ }^{\ddagger}$ external errors are derived from repeat standard analyses during the measurement session; if internal errors are larger than external errors, these are plotted in Figure 1.

n sample was flagged as contaminated by the lab and is not included in the calculated average and not shown in Figure 1.

${ }^{\$}$ lab reported that error bars were larger than usual, and speculated that their new Fe solution was not sufficiently clean.

${ }^{\$ 1}$ lab reported sample loss during preconcentration.

lab 1: $\quad \mathrm{JNd}_{\mathrm{i}}{ }^{143} \mathrm{Ndd} /{ }^{144} \mathrm{Nd}$ ratios of $0.512050 \pm 0.000018$ ( $\mathrm{n}=184 ; 15 \mathrm{ng}$ loads)

lab 2: La Jolla ${ }^{143} \mathrm{Nd} /{ }^{144} \mathrm{Nd}$ of $0.511849 \pm 0.000007$ ( $n=11 ; 50 \mathrm{ppb}$ solution, uptake of $0.3 \mathrm{ml}$ per analysis).

lab 3: La Jolla ${ }^{143} \mathrm{Nd} /{ }^{144} \mathrm{Nd}$ of $0.511845 \pm 0.000021$ ( $\mathrm{n}=10 ; 15 \mathrm{ng}$ loads).

lab 4: La Jolla ${ }^{143} \mathrm{Nd} /{ }^{144} \mathrm{Nd}$ of $0.511851 \pm 0.000012(20 \mathrm{ppb}$ solution)

lab 5: La Jolla ${ }^{143} \mathrm{Nd} /{ }^{144} \mathrm{Nd}$ of $0.511815 \pm 0.000010(\mathrm{n}=1 ; 50 \mathrm{ng}$ load run at low beam intensity to match sample beam): $\mathrm{JNd}_{i}{ }^{143} \mathrm{Nd} /{ }^{144} \mathrm{Nd}$ of $0.512083 \pm 0.000013(\mathrm{n}=8 ; 20 \mathrm{ng}$ loads $)$

lab 6: La Jolla ${ }^{143} \mathrm{Nd} /{ }^{144} \mathrm{Nd}$ of $0.511848 \pm 0.000004$ ( $n=12$, loads of $100-400 \mathrm{ng}$ ). 20 loads of $4-12 \mathrm{ng}$ of an inhouse standard yielded an error of 0.000022 .

lab 7: $\quad \mathrm{JNd}_{\mathrm{i}}{ }^{143} \mathrm{Nd} /{ }^{144} \mathrm{Nd}$ of $0.512103 \pm 0.000014$ ( $\mathrm{n}=65 ; 60 \mathrm{ppb}$ solution)

lab 8: La Jolla ${ }^{143} \mathrm{Nd} /{ }^{144} \mathrm{Nd}$ of $0.511902 \pm 0.000010(n=8 ; 15-30 \mathrm{ng}$ loads $)$.

lab 9: $\quad \mathrm{JNd}^{143} \mathrm{Nd} /{ }^{144} \mathrm{Nd}$ of $0.512098 \pm 0.000017$ ( $\mathrm{n}=6 ; 250 \mathrm{ng}$ loads, often runs one filament repeatedly).

lab 10: Second deep water sample and first shallow water sample have been normalized using a $\mathrm{JNd}_{\mathrm{i}}{ }^{14} \mathrm{Nd} /{ }^{144} \mathrm{Nd}$ of $0.512199 \pm$ 0.000051 ( $n=3 ; 9$ ppb solution); remaining ratios are normalized based on $\mathrm{JNd}_{i}{ }^{143} \mathrm{Nd} /{ }^{144} \mathrm{Nd}$ of $0.512177 \pm 0.000038$ $(n=4 ; 13$ ppb solution).

lab 11: La Jolla ${ }^{143} \mathrm{Nd} /{ }^{144} \mathrm{Nd}$ of $0.511838 \pm 0.000015(\mathrm{n}=4 ; 10 \mathrm{ng}$ loads $)$

lab 12: $\mathrm{JNd}^{143} \mathrm{Nd} /{ }^{144} \mathrm{Nd}$ of $0.512102 \pm 0.000008$ ( $\mathrm{n}=12 ; 5 \mathrm{ng}$ loads)

lab 13: JMC ${ }^{143} \mathrm{Nd} /{ }^{144} \mathrm{Nd}$ of $0.511110 \pm 0.000018$ ( $\mathrm{n}=3 ; 15 \mathrm{ppb}$ solution), calibrated to correspond to a $\mathrm{JNd}_{\mathrm{i}}$ value of 0.512102

lab 15: La Jolla ${ }^{143} \mathrm{Nd} /{ }^{144} \mathrm{Nd}$ of $0.511857 \pm 0.000011$ ( $n=4 ; 10-20 \mathrm{ng}$ loads). oratory environment using distilled acids only. Two different stock solutions (15ppb $\mathrm{Nd}$ in $0.1 \mathrm{M} \mathrm{HNO}_{3}$ and 15 ppm $\mathrm{Nd}$ in $4 \mathrm{M} \mathrm{HNO}_{3}$ ) were prepared from a single digest of the powder, and aliquots were subsequently sent out to each laboratory (15 ppb and $15 \mathrm{ppm}$ solutions dependent on the use of MCICP-MS or TIMS respectively). Concentrations were chosen to mimic those typical for Atlantic seawater. Data returns from 13 laboratories yielded an average $\mathrm{Nd}$ isotopic composition of $-17.3 \pm 0.6$ (Table 4). The two sigma standard deviation of $56 \mathrm{ppm}$ from the mean of all individual measurements is very similar to the reproducibility obtained on seawater samples (47 to 57 ppm). The two sigma standard deviation calculated for each laboratory on the unknown standard solution varies between 11 and $86 \mathrm{ppm}$ (Table 4), which is similar to the range reported by individual laboratories on La Jolla, $\mathrm{JNd}_{\mathrm{i}}$, and other in house standard runs (Tables 2,3; 6-100 ppm). Detailed comparison shows that some laboratories may underestimate their external errors, whereas others report rather conservative errors. Hence, it can be concluded that the major variable in obtaining good agreement for $\mathrm{Nd}$ isotopic measurements between different laboratories is mass spectrometry. Although very different preconcentration methods and ion chromatographic protocols are used by the different laboratories (see Table 1a), these parts of the methodology do not seem to add significantly to the uncertainty of the final results. What has a larger effect, however, on the precision possible during mass spectrometry is the concentration of $\mathrm{Nd}$ analyzed (i.e., counting statistics). Analyses of $15 \mathrm{ng}$ loads by TIMS typically produce more precise results than 15 ppb runs by MC-ICP-MS, an outcome that is expected due to the higher transmission efficiency of TIMS analyses, especially when performed as $\mathrm{NdO}^{+}$(e.g., Li et al. 2007; Chu et al. 2009; Harvey and Baxter 2009). However, $\mathrm{Nd}^{+}$measurements are not necessarily superior to analyses performed on 
Table 3: International intercalibration for $\mathrm{Nd}$ isotopes in seawater at SAFe.

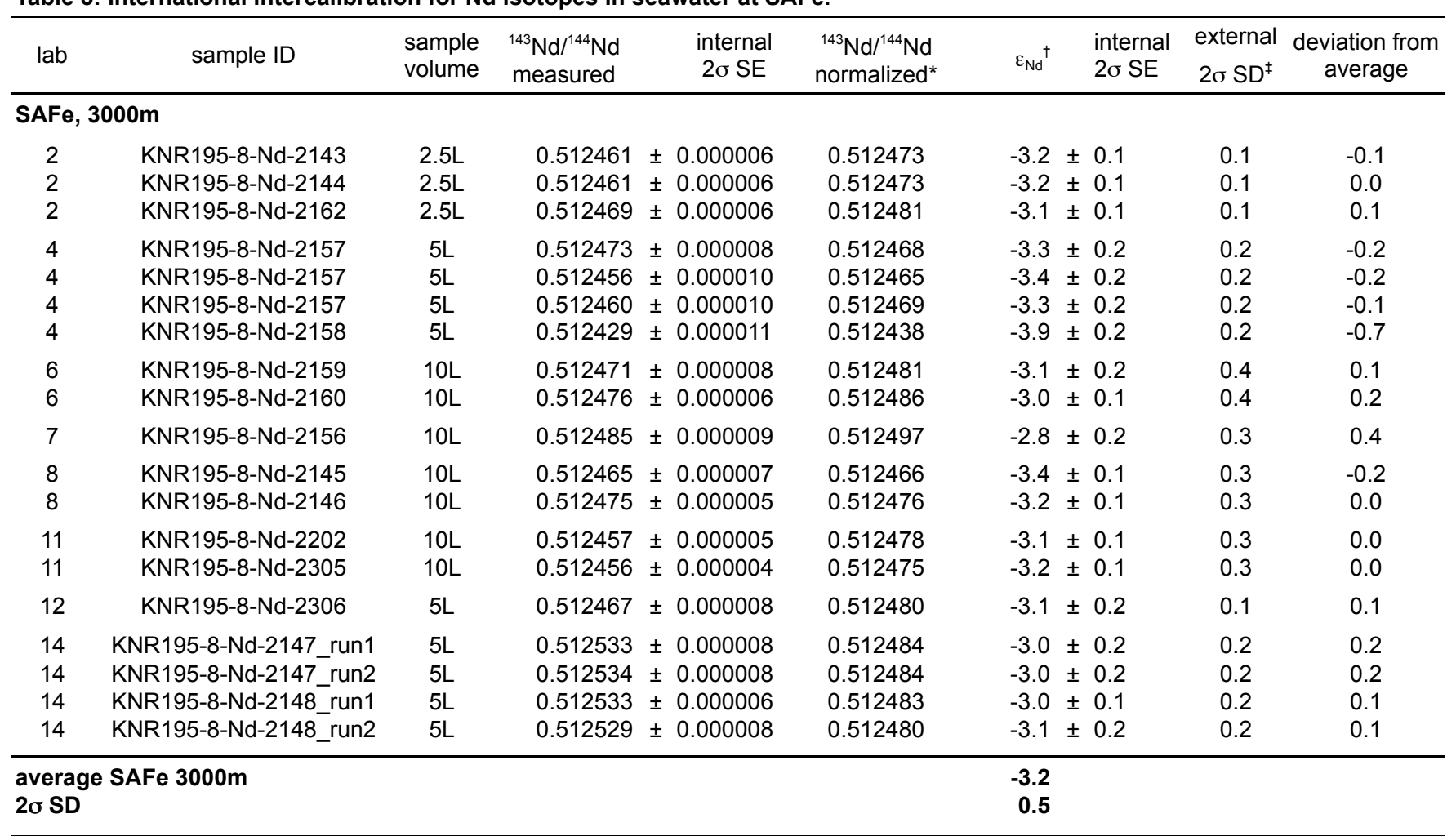

\footnotetext{
${ }^{*}{ }^{143} \mathrm{Nd} /{ }^{144} \mathrm{Nd}$ ratios were normalized using the reported standard data for each lab, relative to a $\mathrm{JNd}_{\mathrm{i}}$ value of 0.512115

Tanaka et al. (2000) or a La Jolla value of 0.511858 (Lugmair et al., 1983).

${ }^{\dagger} \varepsilon_{\mathrm{Nd}}$ values were calculated relative to a CHUR of 0.512638 (Jacobsen and Wasserburg, 1980).

${ }^{\ddagger}$ external errors are derived from repeat standard analyses during the measurement session
}

lab 2: La Jolla ${ }^{143} \mathrm{Nd} /{ }^{144} \mathrm{Nd}$ of $0.511846 \pm 0.000005(n=16)$.

lab 4: Samples were normalised to two measurement sessions yielding $\mathrm{JNd}_{i}{ }^{143} \mathrm{Nd} /{ }^{144} \mathrm{Nd}$ of $0.512120 \pm 0.000008(\mathrm{n}=7)$ and $\mathrm{JNd}_{\mathrm{i}}{ }^{143} \mathrm{Nd} /{ }^{144} \mathrm{Nd}$ of $0.512106 \pm 0.000005(\mathrm{n}=19)$ respectively. For chemical separation: see Table 2.

lab 6: La Jolla ${ }^{143} \mathrm{Nd} /{ }^{144} \mathrm{Nd}$ of $0.511848 \pm 0.000004$ (12 loads of 100-400ng; 19 loads of 10-20ng of an inhouse standard yielded an error of 0.000018 ).

lab 7: $\quad \mathrm{JNdi}^{143} \mathrm{Nd} /{ }^{144} \mathrm{Nd}$ of $0.512103 \pm 0.000014(\mathrm{n}=45)$. For chemical separation: see Table 2 .

lab 8: La Jolla ${ }^{143} \mathrm{Nd} /{ }^{144} \mathrm{Nd}$ of $0.511857 \pm 0.000015(\mathrm{n}=17)$. Samples were processed in lab 8, but analyzed in lab 2 .

lab 11: La Jolla ${ }^{143} \mathrm{Nd} /{ }^{144} \mathrm{Nd}$ of $0.511837 \pm 0.000013(\mathrm{n}=5)$.

lab 12: $\mathrm{JNdi}{ }^{143} \mathrm{Nd} /{ }^{144} \mathrm{Nd}$ of $0.512102 \pm 0.000003(\mathrm{n}=5)$.

lab 14: $\mathrm{JNd}_{\mathrm{i}}{ }^{143} \mathrm{Nd} /{ }^{144} \mathrm{Nd}$ of $0.512164 \pm 0.000011(\mathrm{n}=11 ; 40 \mathrm{ppb}$ solution).

a sensitive MC-ICP-MS (e.g., a set-up that yields large ion beams even for small abundances of Nd; see Fig. 3 and Table 4). The two laboratories that stand out in Fig. 3 with the largest data spread (numbers 7 and 10), both report results from MCICP-MS runs where machine sensitivity hampered a better reproducibility on $15 \mathrm{ppb}$ solutions. In general, a combination of time-resolved analyses, which allows acquisition of isotopic ratios at a faster speed and optimized sample solution concentration to achieve the largest possible Nd beam can potentially improve results (i.e., individual laboratories were requested to run the original $15 \mathrm{ppb}$ solutions).

Returning to the individual results on the Nd isotopic composition of seawater at BATS (Fig. 1; point (2) above), the agreement between laboratories improves from a two sigma standard deviation of $\sim 60 \mathrm{ppm}$ to $\sim 40 \mathrm{ppm}$, when omitting the results for laboratories 6 and 10. There is some justification to look at the results like this, as laboratory 6 reported problems with the Fe solution that they used for the seawater analyses from BATS. As outlined above, Fe solution can be a significant source of blank, and this blank can only be neglected for small abundance samples when isotopically characterized as done by Laboratory 2 (see Table 1a). Laboratory 10 reports replicate values for each water depth that overlap with each other, and also overlap within error with the average from all laboratories. However, error bars are large due to poor external reproducibility on low concentration standard runs. The same laboratory reports an improved external reproducibility of 18 to $37 \mathrm{ppm}$ on $100 \mathrm{ppb}$ standard solution. It is 


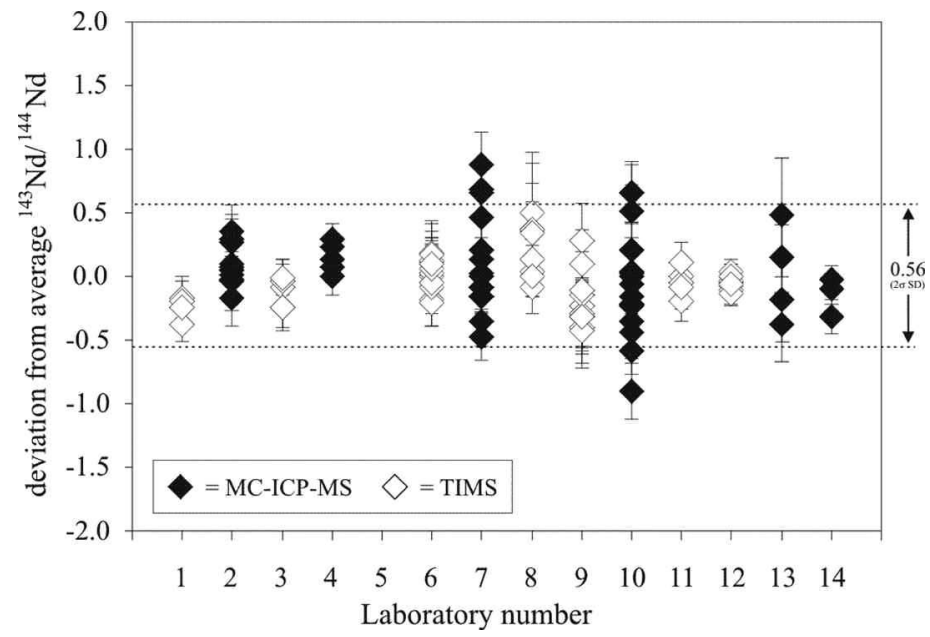

Fig. 3. Neodymium isotopic compositions for an unknown standard solution. The unknown $\mathrm{Nd}$ isotope standard was produced from a pure $\mathrm{Nd}_{2} \mathrm{O}_{3}$ powder. It was distributed in $\mathrm{Nd}$ concentrations that mimic seawater concentrations, without requiring further treatment in individual laboratories (i.e., $15 \mathrm{ppm}$ for TIMS laboratories and $15 \mathrm{ppb}$ for MC-ICPMS laboratories). Analyses by 13 different laboratories yielded a similar reproducibility as reported for seawater analyses (i.e., $56 \mathrm{ppm}$ two sigma standard deviation when taking into account all individual measurements; for seawater results, see Figs. 1 and 2 and Tables 2 and 3). Results furthermore reveal that some laboratories may underestimate their external errors when dealing with low abundance samples (see text for further explanation). Filled symbols: laboratories that carried out analyses by MCICP-MS. Open symbols: laboratories that carried out analyses by TIMS. Errors plotted are internal two sigma standard errors.

important to note that not all laboratories chose to run their isotopic standards at the same concentrations as the samples (see notes in the caption of Table 2). In detail, Laboratories 7 and 9 report results on significantly higher concentrated standards. In the case of Laboratory 9, ion beam intensity however was controlled at a level similar to the one obtained during sample runs. Laboratory 13 reports a much larger reproducibility on the unknown standard than for their in-house standard (76 versus 25-35 ppm; Tables 2 and 4) for unresolved reasons. Overall, some laboratories may underestimate their external errors by not matching standard and sample concentrations. Many laboratories however yield consistent results between 20 and $40 \mathrm{ppm}$ throughout the intercalibration exercise (see captions of Tables 2-4). Furthermore, failure to reproduce individual samples within one laboratory could hint at unidentified blank issues affecting the accuracy of results (Laboratory 4; Fig. 2).

\section{Neodymium isotope intercalibration in marine particles at} BATS

Figure 4 shows the results obtained from six different laboratories on the $\mathrm{Nd}$ isotopic composition of marine particulate matter collected at three different locations in the Atlantic Ocean, using two different pumping systems. Following the discussion above on seawater Nd isotope analyses, the different laboratories can be expected to achieve ${ }^{143} \mathrm{Nd} /{ }^{144} \mathrm{Nd}$ results

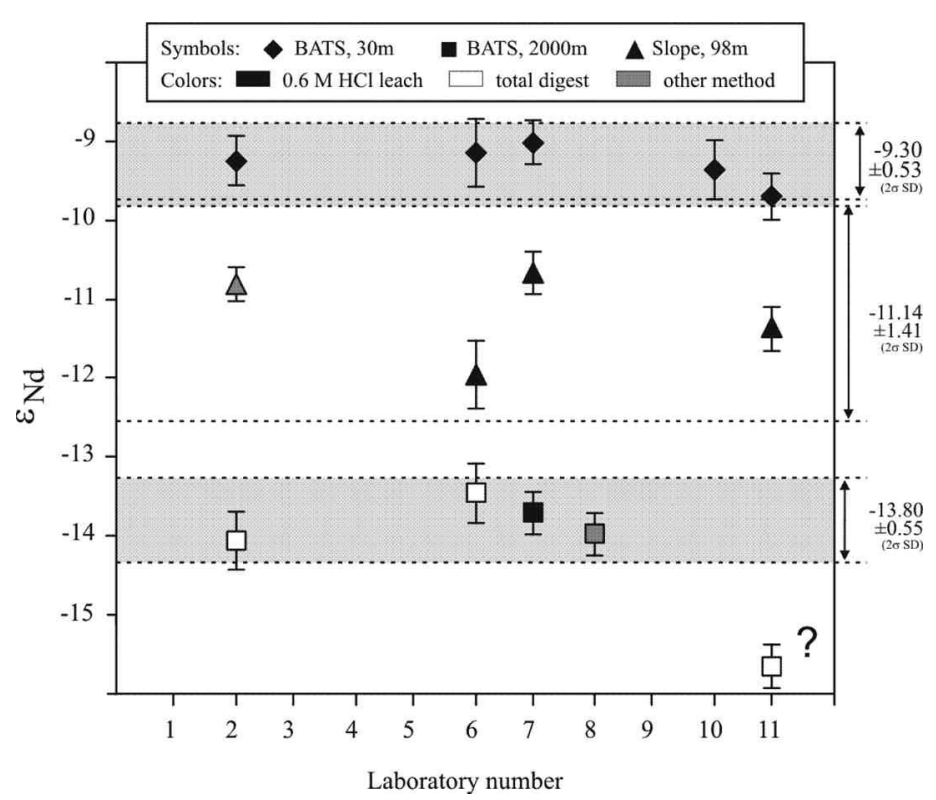

Fig. 4. Neodymium isotopic composition of marine particles collected during the first intercalibration cruise. Results for particle analyses at three different stations: sub-surface water at BATS (top), Virginia continental slope (middle), and deep water at BATS (bottom). Whereas good agreement between different laboratories can be observed for the samples from the shallow water depth at BATS (two sigma standard deviation of $53 \mathrm{ppm}$ ), different leaching/digestion methods used as well as outliers in the analyses make the data for the other two stations inconclusive (two sigma standard deviations worse than 100 ppm; Table 5).

that agree within $\sim 60 \mathrm{ppm}$ if two important preconditions are met: (i) the particle composition on each filter was homogenous and reproducible between filters from the same pumping station, and (ii) all laboratories used the same method to either leach particles off the filter, or to perform a total filter and sample digest.

The first point is discussed in more detail in dedicated papers on analyses and sampling of marine particles (Maiti et al. 2012 and Bishop et al. 2012). The latter point is fulfilled for the particle samples from the shallow water depth at BATS, but violated for the other two intercalibration samples (Fig. 4; Table 5). Considering that any particle sample from the ocean is a mixture of biogenic and detrital particles, each of which could have a distinct Nd concentration and isotopic composition and react differently to different chemical leaching/digestion procedures, we would expect to see some dependence on chosen methodology. The actual results are, however, inconclusive. Particles from the shallow water depth at BATS, all leached using the same prescribed methodology following Jeandel et al. (1995), show an average Nd isotopic composition of -9.3 and agree within 0.5 epsilon units ( $2 \sigma$ standard deviation of the mean; Fig. 4, Table 5). This result could be interpreted as an excellent agreement for an intercalibration, although statistics are hampered by the small number of data submissions $(n=5)$. 
Table 4: Results from individual laboratories on the 'unknown' Nd standard.

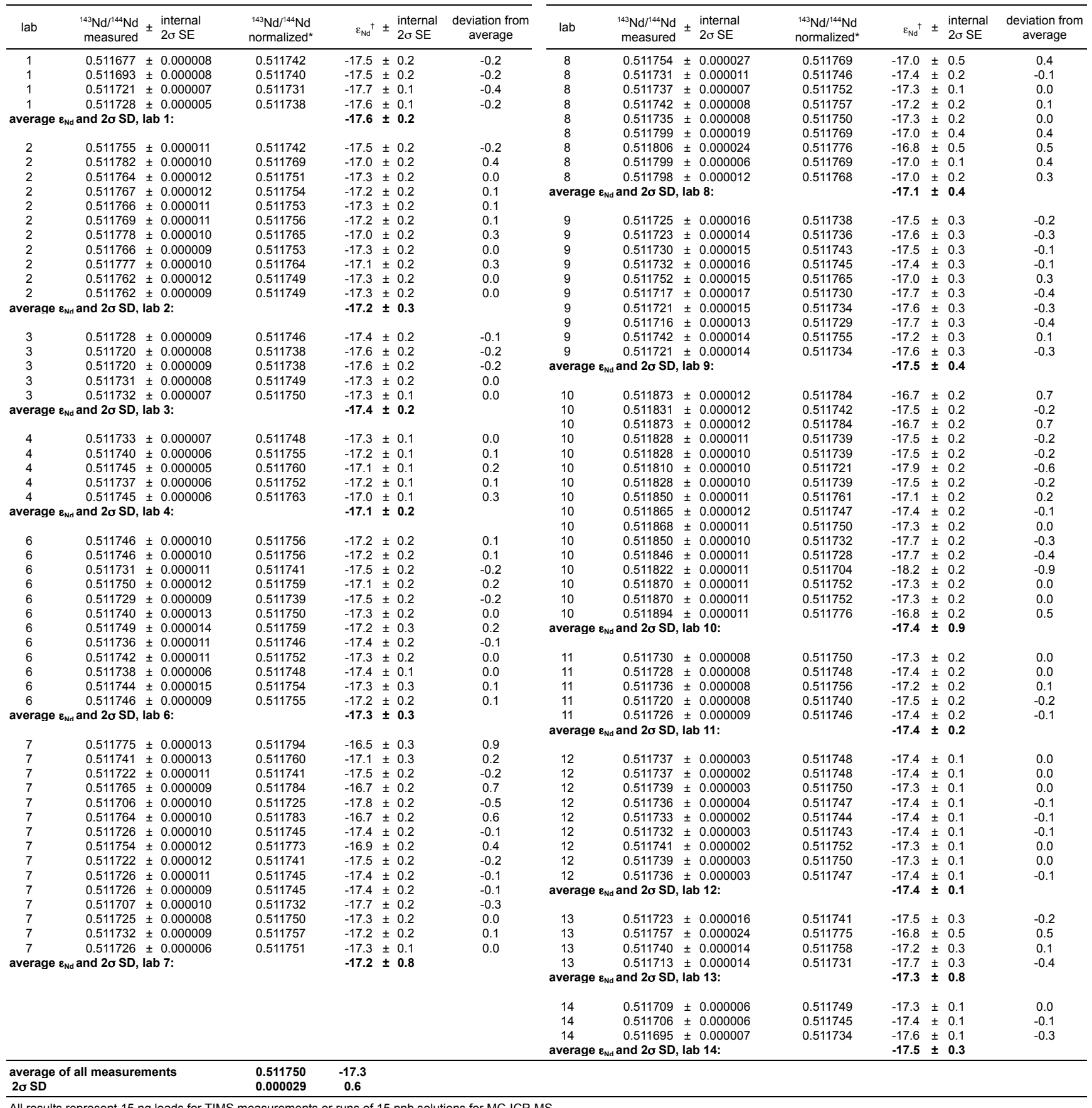

All results represent $15 \mathrm{ng}$ loads for TIMS measurements or runs of $15 \mathrm{ppb}$ solutions for MC-ICP-MS.

${ }^{*}{ }^{143} \mathrm{Nd} /{ }^{144} \mathrm{Nd}$ ratios were normalized using the reported standard data for each lab, relative to a Jnd $\mathrm{i}_{\mathrm{i}}$ value of 0.512115 (Tanaka et al., 2000) or a La Jolla value of 0.5115858 (Lugmair et al., 1983 ).

${ }^{\dagger} \varepsilon_{\text {Nd }}$ values were calculated relative to a CHUR of 0.512638 (Jacobsen and Wasserburg, 1980).

lab 1: First two results are normalized to $\mathrm{JNd}^{1}{ }^{143} \mathrm{Nd} /{ }^{144} \mathrm{Nd}$ ratios of $0.512050 \pm 0.000007$ and $0.512068 \pm 0.000008$ respectively. Latter two results are normalized to a $\mathrm{JNd} \mathrm{i}^{143} \mathrm{Nd} /{ }^{144} \mathrm{Nd}$ of $0.512105 \pm 0.000015(n=6)$

lab 2: La Jolla ${ }^{143} \mathrm{Nd} /^{144} \mathrm{Nd}$ of $0.511871 \pm 0.000008(\mathrm{n}=16)$

lab 3: La Jolla ${ }^{143} \mathrm{Nd} /{ }^{144} \mathrm{Nd}$ of $0.51184 \pm 0.000014(\mathrm{n}=8) ; \mathrm{JNd}_{\mathrm{i}}{ }^{143} \mathrm{Nd} /{ }^{144} \mathrm{Nd}$ of $0.512095 \pm 0.000011(\mathrm{n}=8)$. Values were normalized using the reported La Jolla standards.

lab 4: Results normalized to two different $\mathrm{JNd}_{i}$ values: Results $1-4$ are normalized to a $\mathrm{JNd}_{i}{ }^{1{ }^{13}} \mathrm{Nd} /{ }^{144} \mathrm{Nd}$ of $0.512100 \pm 0.000015(\mathrm{n}=14)$ and result 5 is normalized to a $\mathrm{JNd}_{i}{ }^{143} \mathrm{Nd} /{ }^{144} \mathrm{Nd}$ of $0.512097 \pm 0.000010(n=7)$

lab 6: La Jolla ${ }^{143} \mathrm{Nd} /{ }^{144} \mathrm{Nd}$ of $0.511848 \pm 0.000009(\mathrm{n}=7)$.

lab 7: Results from two different measurement sessions. First 11 ratios are normalized using a $\mathrm{JNd}_{\mathrm{i}}{ }^{143} \mathrm{Nd} /{ }^{144} \mathrm{Nd}$ of $0.512096 \pm 0.000005$ ( $\mathrm{n}=11$ ); remaining ratios are normalized based on $\mathrm{JNd}$ ${ }^{143} \mathrm{Nd} /{ }^{144} \mathrm{Nd}$ of $0.512090 \pm 0.000006(n=11)$

lab 8: First five ratios are the result of dynamic mode analysis normalized to a La Jolla ${ }^{143} \mathrm{Nd} /{ }^{144} \mathrm{Nd}$ of $0.511843 \pm 0.000012(\mathrm{n}=12)$. The last four ratios are the result of static mode analysis normalized to a La Jolla ${ }^{143} \mathrm{Nd} /{ }^{144} \mathrm{Nd}$ of $0.511888 \pm 0.000019(n=12)$.

lab 9: $\quad \mathrm{JNd}_{\mathrm{i}}{ }^{143} \mathrm{Nd} /{ }^{144} \mathrm{Nd}$ of $0.512102 \pm 0.000015(\mathrm{n}=19)$.

lab 10: First 11 ratios are normalized using a $\mathrm{JNd}_{i}{ }^{143} \mathrm{Nd} /{ }^{144} \mathrm{Nd}$ of $0.512090(\mathrm{n}=11)$; remaining ratios are normalized based on $\mathrm{JNd}_{i}{ }^{143} \mathrm{Nd}^{144} \mathrm{Nd}$ of $0.512096(\mathrm{n}=14)$

lab 11: La Jolla ${ }^{143} \mathrm{Nd} /{ }^{144} \mathrm{Nd}$ of $0.511838 \pm 0.000015(\mathrm{n}=4)$.

lab 12: $\mathrm{JNd}^{143} \mathrm{Nd} / /^{144} \mathrm{Nd}$ of $0.512104 \pm 0.000003(\mathrm{n}=4)$.

lab 13: JMC-321 ${ }^{143} \mathrm{Nd} /{ }^{144} \mathrm{Nd}$ of $0.511105 \pm 0.000013(\mathrm{n}=6)$, which was calibrated to correspond to a $\mathrm{JNd}$ value of 0.512097 .

lab 14: Results are relative to a linear drift correction on the day of analyses. $40 \mathrm{ppb} \mathrm{JNd}_{\mathrm{i}}{ }^{143} \mathrm{Nd} / /^{144} \mathrm{Nd}$ of $0.512164 \pm 0.000011(\mathrm{n}=11)$. 
Table 5: International intercalibration for $\mathrm{Nd}$ isotopes in marine particulates.

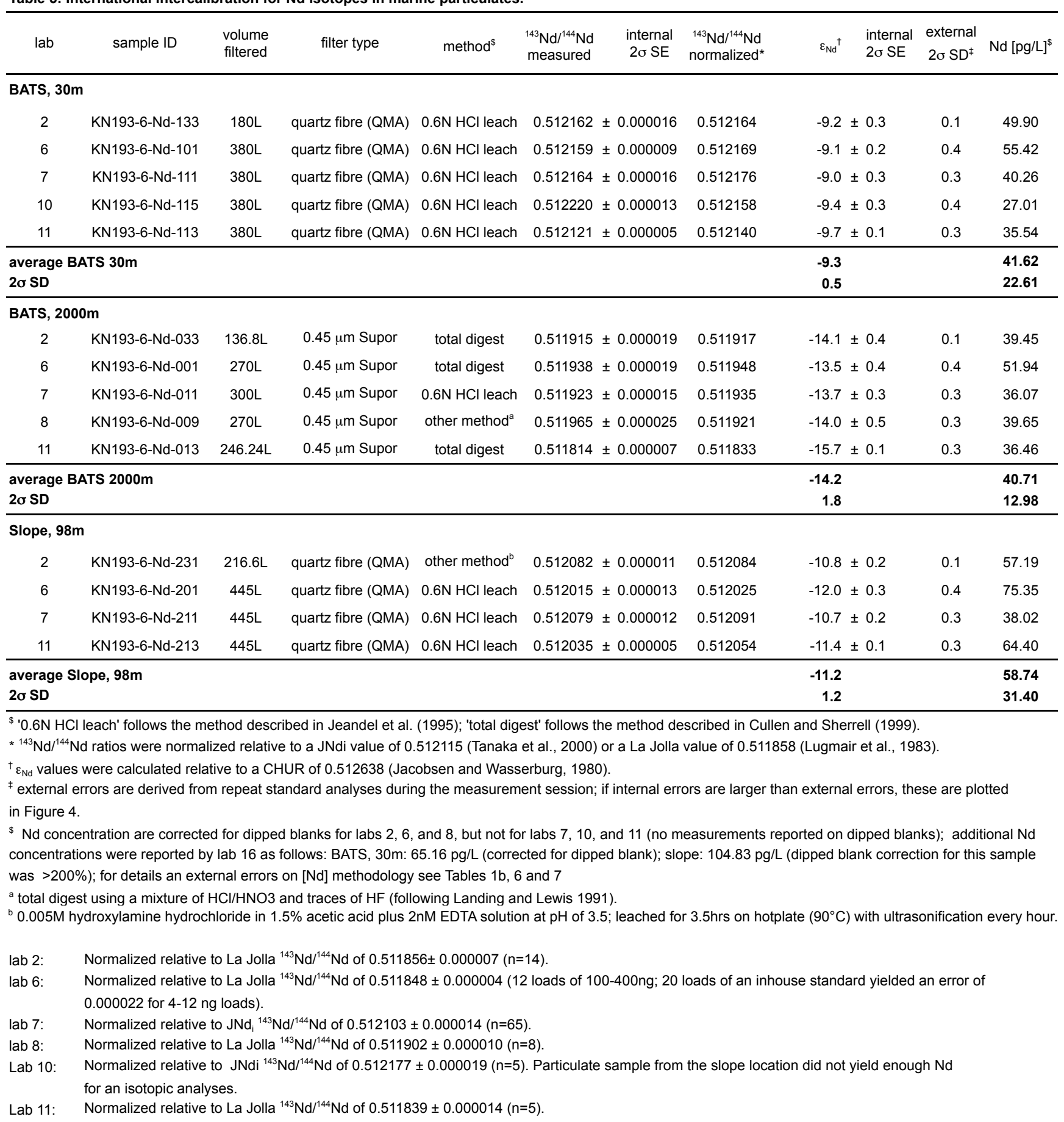

Applying however the same leaching method at the slope station (same filter type, same pumping system) yielded results that do not agree within error (Laboratories 6 and 7: Fig. 4, Table 5).

Similarly, results from four laboratories for the deep water samples at BATS show excellent agreement (mean Nd isotopic composition of $-13.8 \pm 0.6$ ) despite the use of different digestion/leaching methods. Two laboratories (numbers 2 and 6) followed the prescribed method for total digestion of particles and filter material described by Cullen and Sherrell (1999). The method used by Laboratory 8 is not too different (see Landing and Lewis 1991), but Laboratory 7 carried out a $0.6 \mathrm{M}$ $\mathrm{HCl}$ leach. Although using the same digestion method as Laboratories 2 and 6, Laboratory 11 reports a $\mathrm{Nd}$ isotopic composition for deep water particles that deviates significantly from the other results $\left(\varepsilon_{\mathrm{Nd}}=-15.7 \pm 0.3\right)$. 


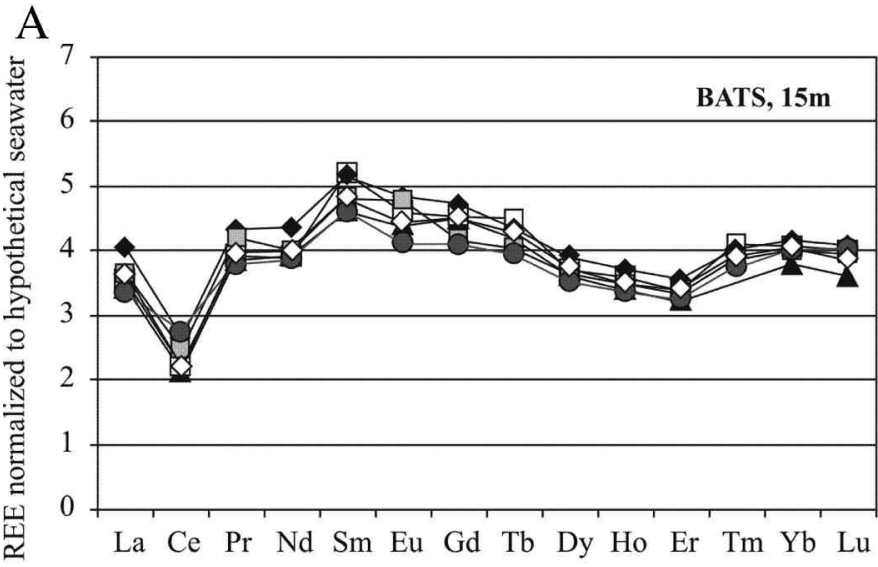

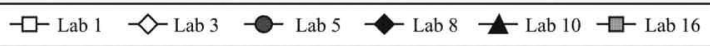

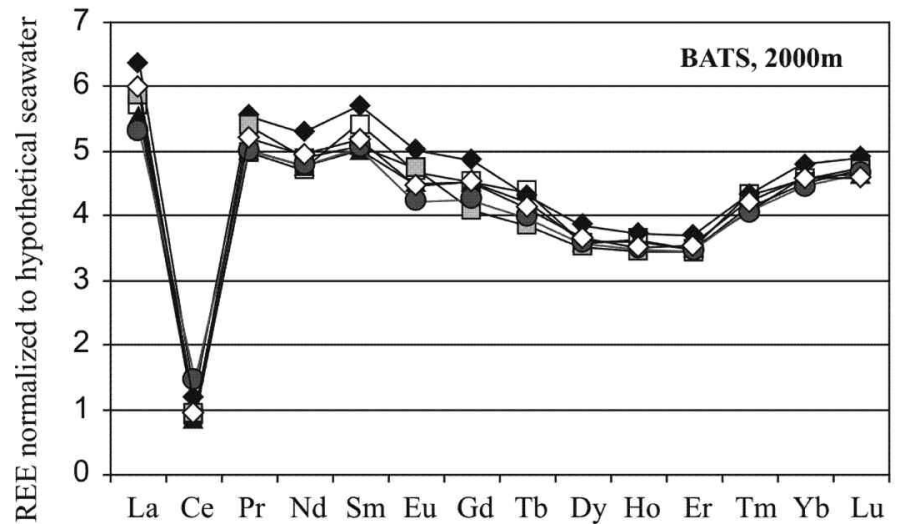

$\mathrm{B}$
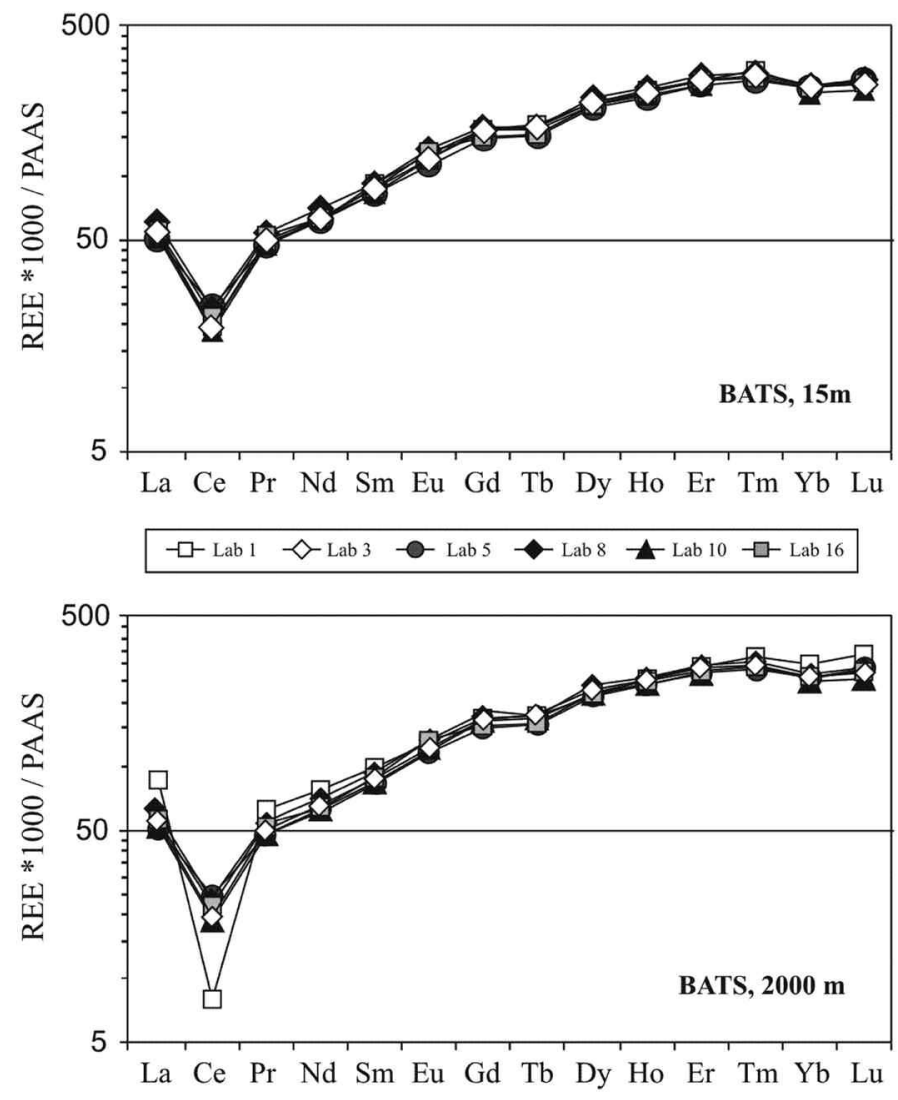

Fig. 5. Dissolved REE concentrations at two water depths at BATS. Results display good agreement between six international laboratories on measuring the concentrations of REE in seawater (e.g., agreement with 15\%, omitting results from laboratory 17; Table 6). (a) REE concentrations normalized to hypothetical seawater of the following composition: La-0.57, Ce-0.7, Pr-0.11, Nd-0.51, Sm-0.1, Eu-0.03, Gd-0.17, Tb-0.03, Dy-0.26, Ho-0.07, Er-0.24, Tm-0.03, Yb-0.18, Lu-0.03 (in [ppt]). (b) REE concentrations normalized to PAAS (Post Archean Australian shale; Nance and Taylor 1976).

At the moment, we can only speculate on the reasons for the inconsistent results reported above, which go along with variable total particle Nd concentrations as well as variable calculated Nd concentrations per pumped amount of seawater (Table 5). Possible explanations include heterogeneous particle distributions on the filters, differences between the filters from individual pumps, or contamination either during sampling, drying, and cutting on the ship, or during processing in the laboratory.

Due to the difficulties with interpreting Nd concentration and isotope data, we refrain at this point from reporting full REE patterns, which were submitted by three laboratories (Laboratories 10, 16, 17).

Rare earth element concentrations in seawater at BATS

Figures $5 \mathrm{a}$ and $5 \mathrm{~b}$ and Table 6 summarize the results for seawater REE concentrations from the two intercalibration samples collected from BATS, analyzed by seven laboratories with significantly different experience levels.

Average REE patterns from all participating laboratories $(1,3,5,8,10,16,17)$, except Laboratory 17 (see discussion below), show agreement within $12 \%$ for deep water at BATS and $15 \%$ for shallow water at BATS (relative $2 \sigma$ SD of the mean = RSD; Table 6). Overall, slightly better agreement is observed for the heavy rare earth elements (HREEs), than for the light rare earth elements (LREE), a result typical for REE measurements. The exception from this overall agreement are Ce concentrations, which display a relative two sigma standard deviation of $44 \%$ for individual results from deep waters and $23 \%$ for results from shallow waters. A potential reason for this large spread in Ce concentrations reported by different labs are significantly higher blank levels for Ce than for other REEs (4\% to 10\%). Those laboratories who measured and reported blanks on their REE concentrations found a shale-like REE pattern, implying larger blank contributions to LREE than HREE.

The best fit to the mean REE pattern is observed for Laboratory 3, which reports all REE except La and Ce within 2\% RSD. This is not surprising as this laboratory used a mixed REE spike consisting of nine individual REE isotopes. Hence isotope dilution calculations could be performed all along the REE spectrum and not just for one or two isotopes as done by 
Table 6 : International intercalibration for REE in seawater at BATS.

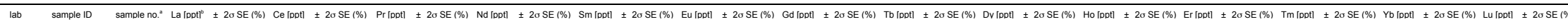

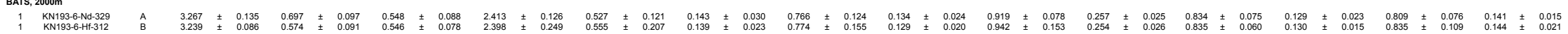

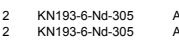

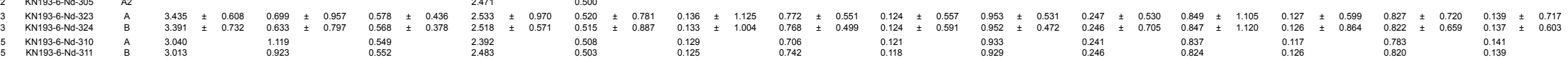

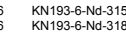

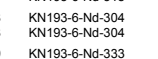

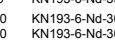

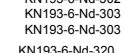

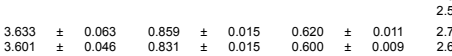

$\begin{array}{llll}2.500 & & & \\ 2.712 & \pm & 0.058 \\ 2.693 & \pm & 0.050 & 0.555\end{array}$

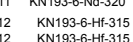

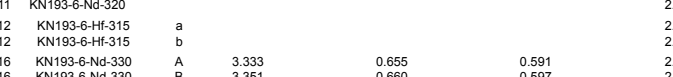

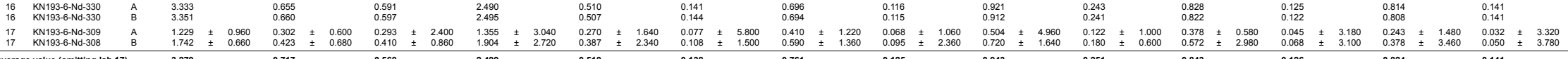

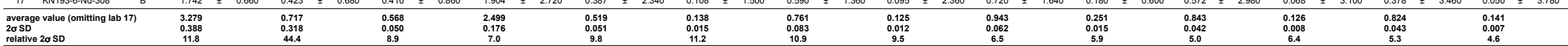

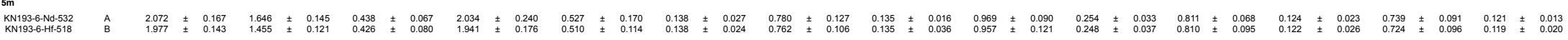

KN193-6-Nad505

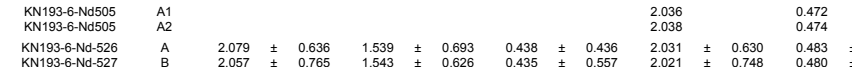

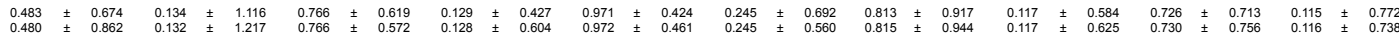

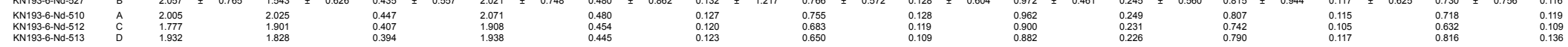

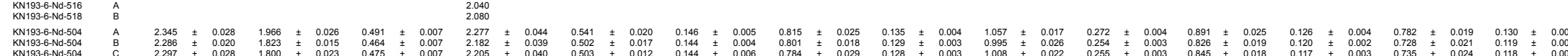

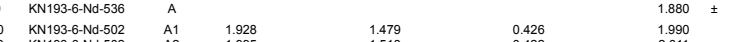

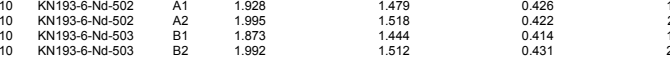

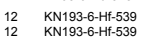

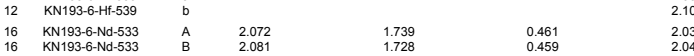

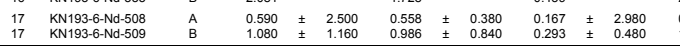

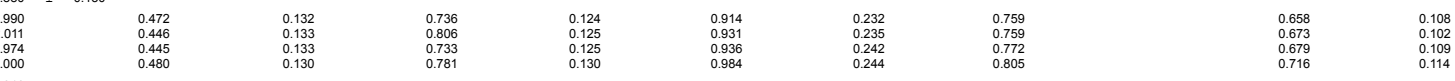

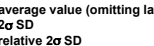

2.048
0.307
15.0

$\begin{array}{lll}1.684 & 0.384 \\ 22.8 & 0.459 \\ 22.8 & 0.052\end{array}$

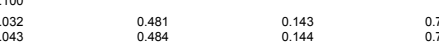

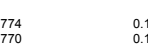

0.122

0951

$\begin{array}{lll}0.116 & 0.715 \\ 0.116 & 0.719 \\ 0.724 & 0.119 \\ 0.36 & +2520 & 0.189\end{array}$

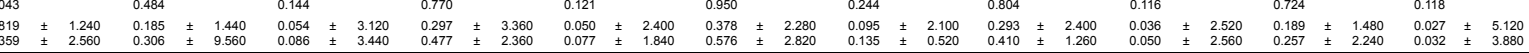

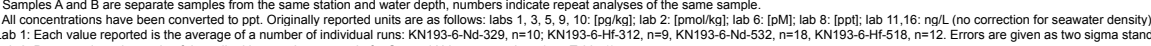

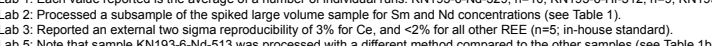

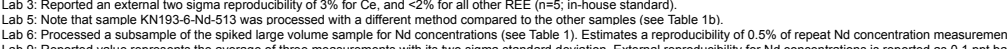

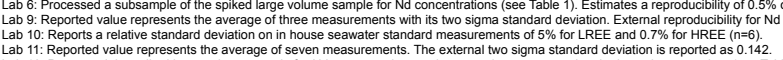

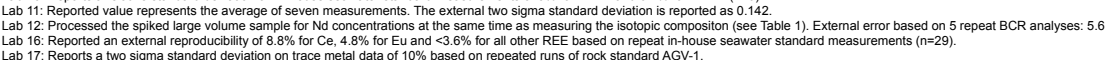

Table 7: Results from individual laboratories on an ' 'nknown' REE standarc.

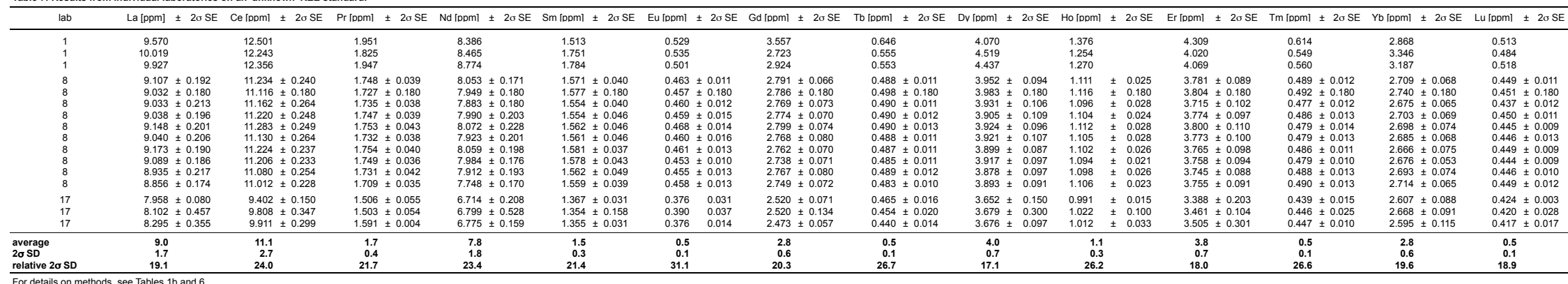


all other laboratories (Table $1 b$ ). A similarly good result is however obtained by Laboratory 10, for the deep water samples where results agree within 3\% RSD with the average values. Laboratories 1, 5, and 16 show deviations from the average within $6 \%$ to $8 \%$ for both water depths, and Laboratory 8 is just outside this margin with agreements within 10\% to $13 \%$ (RSDs cited include all REE but Ce).

How good is the observed agreement? Taking into account that most individual laboratories quote external errors for their methodologies well below $10 \%$, it might be expected that an agreement within $10 \%$ should be possible. The observed agreement is not far from this number, and data returns on an unknown REE standard solution sent to the individual laboratories did not yield an improved agreement over natural samples (Table 7; Fig. 6). The last statement is based on comparison of results from Laboratories 1 and 8, which show an agreement within 10\% for most REE, and 16\% for all REE (relative $2 \sigma \mathrm{SD}$ ).

REE concentrations reported by Lab 17 (not shown in Fig. $5)$ are significantly lower than results obtained by other laboratories ( $30 \%$ to $70 \%)$. Looking into the detail of the methodology applied by this laboratory (Table 1b), a number of factors could be responsible for this offset. First, the laboratory did not spike their concentration samples, which means that imperfect yields and fractionation of REE during preconcentration and ion chromatography cannot be corrected for. Second, the laboratory used the REE cut from their $\mathrm{Nd}$ isotope chemistry to determine REE concentrations, which again stresses that sample recovery up to this point had to be assumed (i.e., 100\% yield). Finally, calculations of REE contents were based on the assumption that the starting sample volume was $10 \mathrm{~L}$, without, however, determining the exact weight before Fe coprecipitation. Shipboard sampling easily introduces an error of $10 \%$ on this assumption, as no efforts were undertaken to collect exact sample volumes. The most likely explanation for the deviation of Laboratory 17 from the average result is therefore a combination of unaccounted sample loss, and an erroneous assumption on sample volume. It is notable that the laboratory significantly improved their methodology for the analysis of the unknown standard. However, the deviation from the average of the two other laboratories is still $11 \%$ to $22 \%$. Further improvement can probably be achieved through close exchange with one of the other laboratories and improved spike calibration.

A better statistical database for evaluating reproducibility of individual REE concentrations can be achieved when considering $\mathrm{Nd}$ concentrations only. Besides the seven laboratories that reported full REE pattern for seawater at BATS, three additional laboratories spiked their large volume isotope samples to determine $\mathrm{Nd}$ concentrations (Laboratories 2, 6, 12), and two other laboratory (9 and 11) obtained separate 0.25 to 0.5 $\mathrm{L}$ aliquots for $\mathrm{Nd}$ concentration measurements (Table 6). Results for Nd concentrations from all 11 laboratories (omitting Laboratory 17) are shown in Fig. 7 for the two intercali-

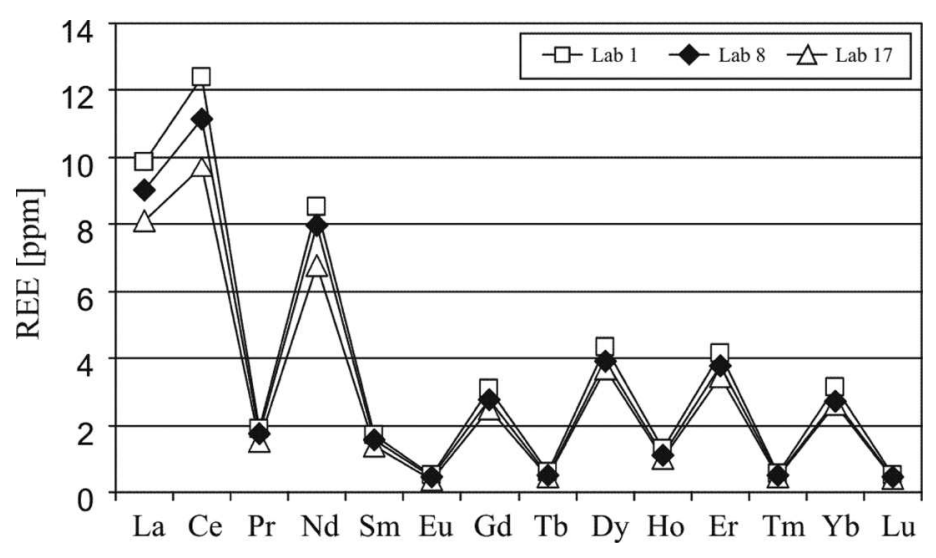

Fig. 6. REE concentrations for an unknown standard solution. Results reported by three laboratories on a pure REE standard solution that was mixed to roughly match seawater concentrations. The standard was sent around with the information that concentrations for $\mathrm{Ce}$ are approximately $10 \mathrm{ppm}$, and that dilutions for analyses should be carried out accordingly. Laboratories 1 and 8 show good agreement, whereas laboratory 17 (not shown in Fig. 5) deviates significantly from the average value.

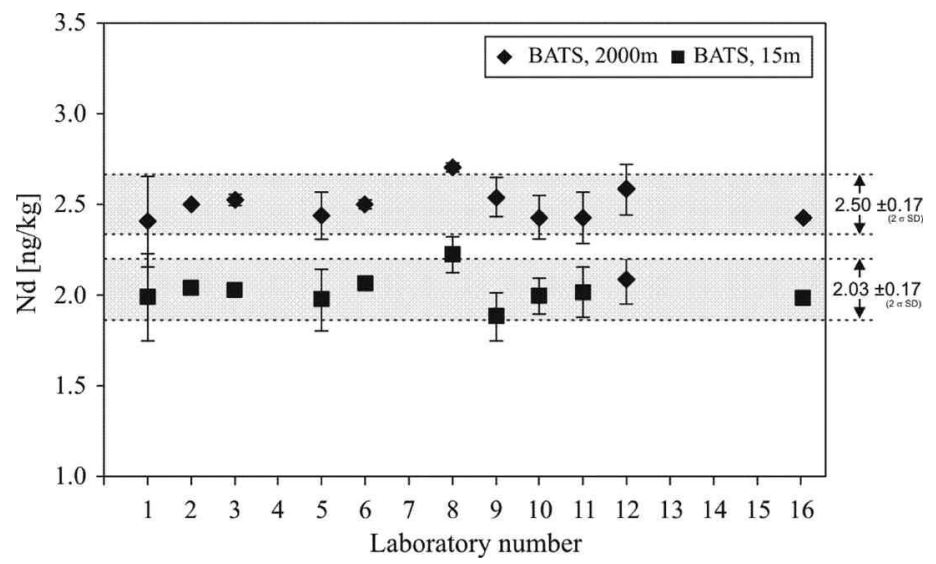

Fig. 7. Dissolved neodymium concentrations at BATS. Neodymium concentrations were not only analyzed by the laboratories interested in REE concentration analyses, but also by some laboratories that are primarily interested in $\mathrm{Nd}$ isotopic compositions. Eleven laboratories (omitting laboratory 17) show an agreement of $\mathrm{Nd}$ concentrations for two different water samples within $9 \%$, reflecting the precision currently possible on REE concentration measurements. Error bars reflect external errors (not reported by every laboratory; see Table 6 ). The average value and its two sigma standard deviation have been calculated from the mean values for each laboratory in order to not weigh the average toward results from laboratories that report larger amounts of individual analyses. For comparison, Table 6 shows the statistics when calculating the average from all individual data points reported.

bration water depths at BATS. Shallow waters yield a Nd concentration of $2.0 \pm 0.2 \mathrm{ng} / \mathrm{kg}$, and deep waters are slightly more concentrated at $2.5 \pm 0.2 \mathrm{ng} / \mathrm{kg}$. Errors are absolute two sigma standard deviations from the mean of all data, which translate to $9 \%$ and $7 \%$ RSD, respectively. This result confirms that a $10 \%$ envelope is probably the best agreement currently possible for REE analyses between different laboratories. 


\section{Summary and recommendations}

Below, we summarize the most important observations from this intercalibration exercise and provide some recommendations for future analyses of Nd isotopes and REE concentrations in seawater and marine particles.

\section{Dissolved Nd isotopes}

Return of results from 15 laboratories that participated in the dissolved $\mathrm{Nd}$ isotope intercalibration at three locations shows agreement within 0.5 to 0.6 epsilon units for

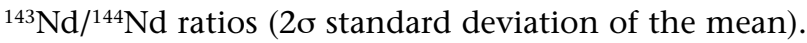

Return of results from 13 laboratories on an unknown $\mathrm{Nd}$ isotope standard solution yields a very similar agreement $(0.6$ epsilon units), suggesting that mass spectrometry is the single most important factor governing interlaboratory precision on $\mathrm{Nd}$ isotope analyses.

Recommendation: Considering the global range of $\mathrm{Nd}$ isotopes in seawater (i.e., more than 20 epsilon units), the result of this intercalibration is very satisfying and no further action is required. A slight improvement can probably be achieved through taking extra care about the blank of the Fe solution used for coprecipitation. Otherwise improvement will depend on the availability of sensitive mass spectrometers and detailed comparison of data reduction protocols during mass spectrometry. To allow rigorous evaluation of the accuracy and precision of seawater $\mathrm{Nd}$ isotope analyses reported by individual laboratories, it is crucial that all laboratories consider for the future to report their external reproducibility based on standard and/or sample analyses of similar concentration to targeted seawater samples.

\section{Dissolved REE concentrations}

Results have been returned from seven laboratories for REE concentrations in seawater. One laboratory has obvious analytical issues, which can be identified and have been discussed with and addressed by the laboratory. All other laboratories show good agreement, with all REE (except Ce) reproducing within $15 \%$ of the average value.

Cerium reproducibility is significantly worse with deviations of $22 \%$ and $44 \%$ from the average value, most likely due to blank contributions. Where analyzed, blanks show a shalelike REE pattern, and hence will have a larger impact on LREE compared with HREE.

Neodymium concentrations determined by 12 laboratories agree within $9 \%$ (with one exception) and probably mark the best reproducibility currently possible for individual REE concentrations.

Recommendation: It would be good if all laboratories would analyze and report the results on a pure standard solution to verify the main source of uncertainty in the reproducibility of REE patterns. Spike calibration seems to be the most likely candidate for variability together with the exact methodology used to calculate concentrations for unspiked elements. The shapes of the REE pattern seem quite robust, but absolute values should not be interpreted to a level better than $10 \%$.

\section{Particles (Nd isotopes and REE concentrations)}

Partial or complete results on $\mathrm{Nd}$ isotopes have been obtained from six laboratories for marine particles. Whereas 0.6 M leaches on particles from the open ocean setting at BATS agree very well, the more particle-rich station on the continental slope shows discrepancies in results, even when the same digestion method is used. Neodymium isotope signatures obtained for particles from deep waters agree fairly well although different leaching/digestion methods have been applied (omitting one outlier). It is unclear at this point whether the described inconsistencies result from sample heterogeneity or analytical artifacts.

Results on Nd concentrations show a large spread and seem to confirm the overall difficulties (at present) with precise analysis of REE concentrations and $\mathrm{Nd}$ isotopic composition in marine particles.

Recommendation: The particle intercalibration should be revisited taking into account results presented in the specific papers (Bishop et al. 2012; Maiti et al. 2012). For the time being, one has to be careful to only compare data obtained by the same leaching/digestion method and probably even from the same laboratory (see also Pahnke et al. 2012).

\section{References}

Alibo, D. S., and Y. Nozaki. 1999. Rare earth elements in seawater: Particle association shale-normalization, and Ce oxidation. Geochim. Cosmochim. Acta 63:363-372 [doi:10.1016/ S0016-7037(98)00279-8].

Bishop, J., P. Lam, T. Wood. In press. Getting good particles: Accurate sampling of particles by large volume in-situ filtration. Limnol Oceanogr. Methods.

Bishop, J. K. B., and T. J. Wood. 2008. Particulate matter chemistry and dynamics in the twilight zone at VERTIGO ALOHA and K2 sites. Deep Sea Res. I 55:1684-1706 [doi:10.1016/j.dsr.2008.07.012].

Chu, Z., F. Chen, Y. Yang, and J. Guo. 2009. Precise determination of $\mathrm{Sm}, \mathrm{Nd}$ concentrations and $\mathrm{Nd}$ isotopic compositions at the nanogram level in geological samples by thermal ionization mass spectrometry. J. Anal. At. Spectrom. 24:1534-1544 [doi:10.1039/b904047a].

Collier, R. W., and J. M. Edmond. 1984. The trace element geochemistry of marine biogenic particulate matter. Progr. Oceanogr. 13:113-199 [doi:10.1016/0079-6611(84)90008-9].

Cullen, J. T., and R. M. Sherrell. 1999. Techniques for determination of trace metals in small samples of size-fractionated particulate matter: phytoplankton metals off central California. Mar. Chem. 67:233-247 [doi:10.1016/S0304-4203 (99)00060-2].

DePaolo, D. J., and G. J. Wasserburg. 1977. The sources of island arcs as indicated by $\mathrm{Nd}$ and $\mathrm{Sr}$ isotopic studies. Geophys. Res. Lett. 4:465-468 [doi:10.1029/GL004i010p00465].

Dodson, R. W., G. J. Forney, and E. H. Swift. 1936. The extraction of ferric chloride from hydrochloric acid solutions by isopropyl ether. J. Amer. Chem. Soc. 58:2573-2577 
[doi:10.1021/ja01303a058].

Elderfield, H., and M. J. Greaves. 1982. The rare earth elements in seawater. Nature 296:214-219 [doi:10.1038/296214a0].

Eugster, O., F. Tera, D. S. Burnett, and G. J. Wasserburg. 1970. The isotopic composition of gadolinium and neutron capture effect in some meteorites. J. Geophys. Res. 75:27532768 [doi:10.1029/JB075i014p02753].

Goldstein, S. L., and S. R. Hemming. 2003. Long-lived isotopic tracers in oceanography, paleoceanography, and ice-sheet dynamics, p. 453-489. In H. D. Holland, K. K. Turekian, and H. Elderfield [eds.], Treatise on geochemistry: The oceans and marine geochemistry. Elsevier.

GEOTRACES Planning Group. 2006. GEOTRACES science plan. Scientific Committee on Oceanic Research.

Halliday, A. N., J. N. Christensen, D. -C. Lee, M. Rehkämper, C. M. Hall, and X. Luo. 2000. Multiple collector inductively coupled plasma mass spectrometry, p. 291-328. In C. B. Barshick, D. C. Duckworth, and D. H. Smith [eds.], Inorganic mass spectrometry: fundamentals and applications. Marcel Dekker.

Harvey, J., and E. F. Baxter. 2009. An improved method for TIMS high precision neodymium isotope analysis of very small aliquots (1-10 ng). Chem. Geol. 258:251-257 [doi:10.1016/j.chemgeo.2008.10.024].

Hooker, P. J., R. K. O’Nions, and R. J. Pankhurst. 1975. Determination of rare-earth elements in USGS standard rocks by mixed-solvent ion exchange and mass-spectrometric isotope dilution. Chem. Geol. 16:189-196 [doi:10.1016/00092541(75)90027-3].

Jacobsen, S. B., and G. J. Wasserburg. 1980. Sm-Nd isotopic evolution of chondrites. Earth Planet. Sci. Lett. 50:139-155 [doi:10.1016/0012-821X(80)90125-9].

Jeandel, C., J. K. Bishop, and A. Zindler. 1995. Exchange of neodymium and its isotopes between seawater and small and large particles in the Sargasso Sea. Geochim. Cosmochim. Acta 59:535-547 [doi:10.1016/0016-7037(94) 00367-U].

Lacan, F., and C. Jeandel. 2005. Neodymium isotopes as a new tool for quantifying exchange fluxes at the continentocean interface. Earth Planet. Sci. Lett. 232:245-257 [doi:10.1016/j.epsl.2005.01.004].

Landing, W. M., and B. L. Lewis. 1991. Analysis of marine particulate and colloidal material for transition metals, p. 263272. In D. C. Hurd and D. W. Spencer [eds.], Marine particles: analysis and characterization. Geophysical Monograph 63. AGU.

Li, C. -F., F. Chen, and X. -H. Li. 2007. Precise isotopic measurements of sub-nanogram $\mathrm{Nd}$ of standard reference material by thermal ionization mass spectrometry using the $\mathrm{NdO}^{+}$technique. Int. J. Mass Spectrom. 266:34-41 [doi:10.1016/j.ijms.2007.06.013].

Lugmair, G. W., N. B. Scheinin, and K. Marti. 1975. Sm-Nd age and history of Apollo 17 basalt 75075: Evidence for early differentiation of the lunar exterior. In Proc. 6th Lunar Sci.
Conf., Pergamon Press, Inc., New York. p. 1419-1429.

- T. Shimamura, R. S. Lewis, and E. Anders. 1983. Samarium-146 in the early solar system: evidence from neodymium in the allende meteorite. Science 222:10151018 [doi:10.1126/science.222.4627.1015].

Maiti, K., and K. O. Buesseler. 2012. 234th intercalibration.

Nance, W. B., and S. R. Taylor. 1976. Rare earth element patterns and crustal evolution-I. Australian post-Archean sedimentary rocks. Geochim. Cosmochim. Acta 40:1539-1551 [doi:10.1016/0016-7037(76)90093-4].

O'Nions, R. K., P. J. Hamilton, and N. M. Evenson. 1977. Variations in the ${ }^{143} \mathrm{Nd} /{ }^{144} \mathrm{Nd}$ and ${ }^{87} \mathrm{Sr} /{ }^{86} \mathrm{Sr}$ ratios in oceanic basalts. Earth Planet. Sci. Lett. 34:13-22 [doi:10.1016/0012821X(77)90100-5].

O’Nions, R. K., S. R. Carter, R. S. Cohen, N. M. Evensen, and P. J. Hamilton. 1978. Pb, $\mathrm{Nd}$ and $\mathrm{Sr}$ isotopes in oceanic ferromanganese deposits and ocean floor basalts. Nature 273:435-438 [doi:10.1038/273435a0].

Pahnke, K., T. van de Flierdt, K. Jones, S. R. Hemming, and S. L. Goldstein. 2012. GEOTRACES intercalibration of neodymium isotopes and rare earth element concentrations in seawater and particles-Part 2: systematic tests and baseline profiles. Limnol Oceanogr. Methods 10:252-269 [doi:10.4319/lom.2012.10.252].

Piepgras, D. J., and S. B. Jacobsen. 1988. The isotopic composition of neodymium in the North Pacific. Geochim. Cosmochim. Acta 52:1373-1381 [doi:10.1016/0016-7037(88) 90208-6].

— elements in seawater: Precise determination of variation in the North Pacific water column. Geochim. Cosmochim. Acta 56:1851-1862 [doi:10.1016/0016-7037(92)90315-A].

, and G. J. Wasserburg. 1980. Neodymium isotopic variations in seawater. Earth Planet. Sci. Lett. 50:128-138 [doi:10.1016/0012-821X(80)90124-7].

- and - 1987. Rare earth element transport in the western North-Atlantic inferred from $\mathrm{Nd}$ isotopic observations. Geochim. Cosmochim. Acta 51:1257-1271 [doi:10.1016/0016-7037(87)90217-1].

-, G. J. Wasserburg, and E. J. Dasch. 1979. The isotopic composition of $\mathrm{Nd}$ in different ocean masses. Earth Planet. Sci. Lett. 45:223-236 [doi:10.1016/0012-821X(79)90125-0].

Pin, C., and J. F. S. Zalduegui. 1997. Sequential separation of light rare-earth elements, thorium and uranium by miniaturized extraction chromatography: Application to isotopic analyses of silicate rocks. Anal. Chim. Acta 33:79-89 [doi:10.1016/S0003-2670(96)00499-0].

Richard, P., N. Shimizu, and C. J. Allègre. $1976 .{ }^{143} \mathrm{Nd} /{ }^{146} \mathrm{Nd}$, a natural tracer: an application to oceanic basalts. Earth Planet. Sci. Lett. 31:269-278 [doi:10.1016/0012-821X(76) 90219-3].

Shabani, M. B., T. Akagi, and A. Masuda. 1992. Preconcentration of trace rare-earth elements in seawater by complexation with bis(2-ethylhexyl) hydrogen phosphate and 2-eth- 
ylhexyl dihydrogen phosphate adsorbed on a C18 cartridge and determination by inductively coupled plasma massspectrometry. Anal. Chem. 64:737-743 [doi:10.1021/ac000 31a008].

Stordal, M. C., and G. J. Wasserburg. 1986. Neodymium isotopic study of Baffin Bay water: sources of REE from very old terranes. Earth Planet. Sci. Lett. 77:259-272 [doi:10.1016/0012-821X(86)90138-X].

Tachikawa, K., V. Athias, and C. Jeandel. 2003. Neodymium budget in the modern ocean and paleo-oceanographic implications. J. Geophys. Res. 108:3254 [doi:10.1029/1999 JC000285].

Tanaka, T., and others. 2000. JNdi-1: a neodymium isotopic reference in consistency with LaJolla neodymium. Chem. Geol. 168:279-281 [doi:10.1016/S0009-2541(00)00198-4].

Thirlwall, M. F. 1991a. Long-term reproducibility of multicollector Sr and Nd isotope ratio analysis. Chem. Geol. 94:85104 [doi:10.1016/S0009-2541(10)80021-X].

. 1991b. High-precision multicollector isotopic analysis of low levels of $\mathrm{Nd}$ as oxide. Chem. Geol. 94:13-22 [doi:10.1016/S0009-2541(10)80013-0].

Vance, D., and M. Thirlwall. 2002. An assessment of mass discrimination in MC-ICPMS using Nd isotopes. Chem. Geol.
185:227-240 [doi:10.1016/S0009-2541(01)00402-8].

, A. E., Scrivner, P. Beney, M. Staubwasser, G. M. Henderson, and N. C. Slowey. 2004. The use of foraminifera as a record of the past neodymium isotope composition of seawater. Paleoceanography 19:PA2009 [doi:10.1029/2003 PA000957].

Weis, D., and others. 2006. High-precision isotopic characterization of USGS reference materials by TIMS and MC-ICPMS. Geochem. Geophys. Geosys. 7:Q08006 [doi:10.1029/2006GC001283].

White, W. M., and J. Patchett. 1984. Hf-Nd-Sr isotopes and incompatible element abundances in island arcs: implications for magma origins and crust-mantle evolution. Earth Planet. Sci. Lett. 67:167-185 [doi:10.1016/0012-821X(84) 90112-2].

Wombacher, F., and M. Rehkämper. 2003. Investigation of the mass discrimination of multiple collector ICP-MS using neodymium isotopes and the generalised power law. J. Anal. At. Spectrom. 18:1371-1375 [doi:10.1039/b308403e].

Submitted 25 July 2011

Revised 8 February 2012

Accepted 14 February 2012 